\title{
Descriptive and Experimental Analysis of the Dispersion of Neural Crest Cells along the Dorsolateral Path and Their Entry into Ectoderm in the Chick Embryo
}

\author{
C. A. Erickson, ${ }^{*}, 1$ T. D. Duong, ${ }^{*}$ ann K. W. TOSney $\dagger$ \\ *Department of Zoology, The University of California, Davis, California 95616; and $\dagger$ Biology Department, \\ The University of Michigan, Ann Arbor, Michigan 48109
}

Accepted January 17, 1991

\begin{abstract}
We have characterized the dispersion of neural crest cells along the dorsolateral path in the trunk of the chicken embryo and experimentally investigated the control of neural crest cell entry into this path. The distribution of putative neural crest cells was analyzed in plastic sections of embryos that had been incubated for $24 \mathrm{hr}$ in HNK-1 antibody, a procedure that we show successfully labels neural crest cells in the dorsolateral path and ectoderm. In accord with earlier observations, crest cells delay entering the dorsolateral path until a day or more after their counterparts have colonized the ventral path. However, once erest cells enter, they disperse rapidly through the path dorsal to the somitc but still delay migrating dorsal to the intersegmental space. During dispersion, crest cells invade the ectoderm at sites associated with local disruptions in the basal lamina which may be caused by crest cells. Finally, deleting the dermamyotome releases an inhibition of neural crest cell migration: crest cells enter the dorsolateral path precociously. We speculate that the epithelial dermatome may transiently produce inhibitory substances and that emerging dermis may provide a long-distance, stimulatory cue. C1992 Academic Press, Inc.
\end{abstract}

\section{INTRODUCTION}

Although the avian neural crest has been used to study the control of cellular migration (cf, Le Douarin, 1982), only one of the two major neural crest paths in the trunk of the avian embryo has received extensive attention. The environmental factors that direct neural crest cell migration along the ventral path through the somites have been studied in detail (e.g., Rickmann et al., 1985; Mackie et al., 1988; Perris et al., 1991), whereas those embryonic features that control crest cell migration into the dorsolateral path between the ectoderm and the somites have been largely neglected. Our study focuses on three issues that are important to understanding how migration into the dorsolateral path is controlled. First, when do neural crest cells enter the dorsolateral path? Second, when do neural crest cells in the dorsolateral path leave the dermis and enter the ectoderm? Third, what environmental features control the entry of neural crest cells into the dorsolateral path?

Neural crest cells that migrate within the dorsolateral path are the precursors of pigment cells that will populate the dermis and ectoderm (DuShane, 1935; Dorris, 1939; Rawles, 1947; Teillet, 1971; Mayer, 1973) but only in amphibians is pigment expressed early

${ }^{1}$ To whom correspondence should be addressed. enough to serve as a marker for these cells during their initial migration (see Löfberg et al., 1980; Tucker and Erickson, 1986). Consequently, the migration of these cells in avian and mouse embryos has been studied largely by indirect means. For instance, several researchers (Willier and Rawles, 1940; Ris, 1941; Watterson, 1942; Fox, 1949; Mayer, 1973; Hulley et al., 1991) attempted to determine when neural crest cells enter dermis and ectoderm by isolating each of these tissues from different developmental stages and asking when melanocytes differentiated in the excised tissues. While this approach can roughly distinguish when crest cells invade an excised tissue, all morphological details are lost. Consequently, the relative timing of crest entry into ventral versus dorsolateral paths cannot be determined, and the environmental features controlling crest dispersion cannot be analyzed. Moreover, if ectoderm is isolated without enzymatic digestion, as in most of these studies, the ectoderm is invariably contaminated with dermis. Therefore, this approach cannot distinguish reliably between times when crest cells had actually invaded the ectoderm and times when they were only dispersed in the closely apposed dermis.

Morphological details are retained in studies that combine various markers with embryonic transplantation (e.g., Weston, 1963; Teillet, 1971), but no studies have used this approach to relate migration into the dorsolateral path. Two recent studies of neural crest migration have, however, used a direct labeling method 
that circumvents the complications of transplantation. The lipophilic dye, DiI, was injected into the lumen of neural tubes in chick or mouse embryos before crest cells emigrated (Serbedzija et al., 1989, 1990). Crest cells were shown to populate embryonic sites in a ventral-todorsal order, with the last crest cells migrating exclusively along the dorsolateral path, confirming the temporal patterns of dispersion previously inferred by less direct methods (Weston, 1970; see also Weston and Butler, 1966). However, these studies did not document in detail when neural crest cells first enter the dorsolateral path. Moreover, this approach virtually precludes a direct comparison of crest cell progression with environmental features since only a portion of the presumptive crest cells are labeled in any one embryo and since the frozen sections used prevent good visualization of nonlabeled tissues.

In the present study we analyzed neural crest cell migration in plastic sections, which optimally preserve morphological detail. We used the HNK-1 antibody, which numerous researchers have used to label neural crest cells during early development (e.g., Vincent et al., 1983; Vincent and Thiery, 1984; Rickmann et al., 1985; Bronner-Fraser, 1986; Teillet et al., 1987; Loring and Erickson, 1987). It is widely believed that this antibody does not recognize the subpopulation of neural crest cells that enter the dorsolateral path (e.g., BronnerFraser, 1986; Loring and Erickson, 1987). However, we show that, with our preparation method, the HNK-1 antibody does label these neural crest cells.

Using the HNK-1 antibody, we detail the patterns and timing of neural crest cell migration into and along the dorsolateral path and into the ectoderm and we confirm that migration into the dorsolateral path is delayed relative to migration ventrally. Moreover, we establish experimentally that the path is transiently inhibitory; crest cells enter the path precociously if the dermamyotome has been previously deleted. Our descriptive and experimental results support the contention that neural crest entry into the dorsolateral path is largely controlled by the dermatome.

\section{MATERIALS AND METHODS}

\section{Anlibody Slaining and Plaslic Embedding}

The distribution of HNK-1-positive cells was observed in embryos that had been permeabilized with antibody and then embedded in plastic, as described in detail previously (Loring and Erickson, 1987; Erickson et al., 1989). With this method, preservation of tissues and resolution of details are greatly improved over tissue embedded in either paraffin or Tissue-Tek, and staining of crest cells in the dorsolateral path is en- hanced. Briefly, embryos between stages 17 and 26 (Hamburger and Hamilton, 1951) were fixed for $1 \mathrm{hr}$ in $4 \%$ paraformaldehyde, rinsed in PBS, and cut transversely to isolate five to six segments of tissue at the levels of the forelimb, the hindlimb, and, less frequently, the thoracic region. The embryo pieces were washed for $3 \mathrm{hr}$ in $3 \%$ bovine serum albumin (BSA) in PBS and then incubated overnight at $4^{\circ} \mathrm{C}$ in $\mathrm{HNK}-1$ antibody (hybridoma ascites; 1:250 in PBS/BSA). The unbound antibody was washed out with a $3-\mathrm{hr}$ incubation in $0.5 \% \mathrm{BSA}$ in PBS and the specimens were immersed overnight in the secondary antibody conjugated with rhodamine (goat anti-mouse IgG + IgM + IgA; 1:50 in PBS; Cappell). After several rinses in PBS the specimens were postfixed in $0.1 \%$ paraformaldehyde for $1 \mathrm{hr}$, dehydrated in acetone, and embedded in Spurr's plastic. The specimens were sectioned at $3 \mu \mathrm{m}$ with a Reichert ultramicrotome and the serial sections collected on glass slides in individual drops of water. After the sections dried to the slide, they were mounted in $70 \%$ glycerol containing $0.1 \mathrm{M} \mathrm{NaHCO}_{3}, \mathrm{pH} 7.8$, and $2 \% n$-propyl gallate as an antioxidant and viewed with a Leitz Dialux 20 microscope equipped with epifluorescence and a Vario Orthomat camera.

\section{DiI Injections and Double Label with HNK-1}

We sought to confirm that HNK-1-positive cells were crest cells by using independent criteria. Our strategy was to label crest cells with a vital dye, 1,1-dioctadecyl$3,3,3^{\prime}, 3^{\prime}$-tetra-methylindocarbocyanine perchlorate (DiI; Molecular Probes, Junction City, OR), before they began to migrate and then to ask if the DiI-labeled cells that had entered the dorsolateral path were also HNK-1-positive. To label premigratory crest cells, we injected DiI as a $5 \%$ solution in $50 \%$ ethanol into the lumen of stage 17 chick neural tubes as described elsewhere (Serbedzija et al., 1989). Embryos were allowed to develop until stage 22 and were then fixed and processed for frozen sections as follows. Embryos were fixed in $4 \%$ paraformaldehyde for $1 \mathrm{hr}$, washed with several changes of PBS, and then soaked in a 15\% sucrose solution for $1 \mathrm{hr}$. The specimens were transferred to $30 \%$ sucrose, incubated overnight at $4^{\circ} \mathrm{C}$, embedded in Tissue-Tek O.C.T. compound (Miles Scientific), immediately frozen in liquid nitrogen, and sectioned at 10-12 $\mu \mathrm{m}$ with a Bright cryostat. Sections were collected on gelatin-subbed slides and, after drying, were washed with PBS and incubated with the HNK-1 antibody (1:250 in PBS/BSA) for $1 \mathrm{hr}$ at room temperature. After several washes in PBS, sections were incubated in a fluorescein-conjugated secondary antibody (goat anti-mouse; 1:50; Cappell) for $30 \mathrm{~min}$, 
washed, mounted as described for plastic sections, and viewed immediately.

\section{Determination of Cell Types Contacted by Migrating Crest Cells}

The relatively high resolution afforded by plastic sections allowed us to determine what cell surfaces the HNK-1-reactive cells might be using for migration. We examined serial sections through at least three contiguous somites at the level of both forelimb and hindlimb at stages 20,22 , and 23.5 , and in every section judged whether each labeled cell in the dorsolateral path was contacting the ectoderm or the dermatome, or was suspended in the extracellular matrix or dermal mesenchyme. We considered a cell to be "in contact" with the surface of the ectoderm or the epithelial dermatome if it was closely applied to the surface and was deformed by its apposition with the putative substratum.

\section{Preparation of Plastic Sections for Transmission Electron Microscopy}

To better resolve HNK-1-positive cells that were in the process of invading the ectoderm, we processed selected sections for transmission electron microscopy (TEM). We first photographed sections in which antibody-labeled cells were either closely applied to the ectoderm or partly into the ectoderm and then reembedded these sections in plastic (for details see Erickson, 1987) and thin-sectioned them with a diamond knife. The sections were stained with uranyl acetate and lead citrate and examined in a Philips 401 transmission electron microscope. The crest cells were relocated in the TEM by referring to the fluorescence photograph of the corresponding section.

\section{Embryonic Surgeries}

To analyze experimentally one environmental feature that may control neural crest entry into the dorsolateral path, we deleted the dermamyotome, the precursor of the dermatome, which lines the ventral border of this path. Methods are described in more detail elsewhere (Tosney, 1987). In brief, egg shells were windowed and the embryos lightly stained with $0.2 \%$ neutral red in distilled water. The ectoderm posterior to the deletion site was slit using a fine tungsten needle and one or more dermamyotomes were removed by suction into a small micropipette (tip size 10-30 $\mu \mathrm{m}$ ) attached to polyethylene tubing. Deletions were confined to the six most recently formed somites at the hindlimb level (approximately somites 22 through 31 ) where neural crest cells had yet to begin migrating. Forty-one operated embryos were subsequently fixed between stages 20 and 26 .

\section{Reconstruction of the Positions of HNK-1-Positive Cells}

To assess the migration patterns accurately, we reconstructed the position of labeled cells as viewed from the dorsal surface. The distribution of HNK-1-positive cells was mapped over at least three somites at both forelimb and hindlimb levels at stages $20,21,22$, and 23.5. Two or more different embryos were mapped at each of these stages. Only one embryo was mapped at stage 26 since, by this stage, fewer cells are labeled with HNK-1 and the label is lighter. The reduction in labeling of premelanocytes in older embryos is not surprising since the HNK-1 epitope is lost from neural crest cells in culture as they differentiate into pigment cells (Vincent and Thiery, 1984).

Maps were reconstructed from camera lucida tracings of serial, transverse sections. The position of each labeled cell in or just proximal to the dorsolateral path was noted on tracings of each section, taking care to record only once any cell that was visible in adjacent sections. The position of each HNK-1-positive cell was then transferred to dorsal-view maps which had been "flattened" to display the positions of all the labeled cells relative to each other and to the underlying dermatome. HNK-1-labeled cells were represented by dots if they lay within the dorsolateral path and by stars if they were in the ectoderm.

The distribution of HNK-1-positive cells was mapped in a similar manner in six stage 20 to 24 embryos in which dermamyotomes had been removed. In addition, the position of any dermatome remnants was carefully recorded and portrayed on the maps with hatched lines. To avoid confusing cells in the anterior sclerotome with cells in the dorsolateral path when there was no intervening dermatome and myotome, we conservatively considered that cells were in the dorsolateral path if they were within three cell widths of the ectoderm. The patterns of migration were confirmed by visual observation in 30 additional embryos.

\section{RESULTS}

\section{HNK-1 Labels Neural Crest Cells in the Dorsolateral Path}

To confirm the utility of HNK-1 as a melanoblast marker, we determined whether neural crest cells that had been labeled by DiI before they began to migrate could be labeled with HNK-1 once they had progressed into the dorsolateral path. Despite the poorer preservation in frozen sections and despite the need for a proto- 
col that was suboptimal for preservation of both DiI and HNK-1, we found double-labeled cells in the three embryos we examined in detail (Fig. 1). Ninety-eight percent of the cells labeled with DiI were also labeled with HNK-1. The appearance of both labels in a single cell did not result from bleed-through with our filter sets because the two labels were often in different locations in an individual cell and because HNK-1 distribution was generally uniform, whereas DiI was punctate. Cells labeled only with DiI were rare ( 2 of 50 cells observed) and these may have lost the HNK-1 label, which is more poorly preserved in these preparations. Cells labeled only with HNK-1 were common, which was expected since DiI injected at any particular stage labels only the subset of neural crest cells that have yet to emigrate from the neural tube (see Serbedzija et al., 1989, 1990). These results substantiate our contention that HNK-1 does label neural crest cells as they invade the dorsolateral path. We will therefore refer to all cells labeled with HNK-1 in the dorsolateral path as neural crest cells.

\section{Temporal and Spatial Distribution of Neural Crest Cells in the Dorsolateral Path}

Neural crest cell migration into the dorsolateral path is initiated in an anterior to posterior wave. The anterior to posterior progression is most obvious when forelimb and hindlimb levels are compared in the same embryos (compare Figs. 3, 5, 7). Neural crest cells first enter the dorsolateral path at the level of the forelimb in stage 20 embryos ( $3 \frac{1}{2}$ days of incubation; Figs. 2C, 2D, 3), whereas in the developmentally younger hindlimb region in the same embryo, neural crest cells have yet to enter this path (Figs. 2A, 2B, 3). The anterior to posterior progression of crest cells into the dorsolateral path is not surprising; the initial emigration of crest cells from the neural tube and their entry into the ventral path also proceed from anterior to posterior (e.g., Weston, 1963; Tosney, 1978; Loring and Erickson, 1987).

Crest cells delay entering the dorsolateral path until more than a day after crest cells have entered the ventral path at the same axial level. For example, at stage 20 , crest cell migration along the ventral path is very well advanced at both forelimb and hindlimb levels: precursors of the sympathetic ganglion have reached their destination around the dorsal aorta and a dorsal root ganglion has condensed. In contrast, neural crest cells have yet to enter the dorsolateral path at hindlimb levels and have only just begun to invade this path at the forelimb level (Fig. 2). Although crest cells in principle have equal access to dorsolateral and ventral paths since they emigrate from the neural tube into the space just medial to the dermatome, crest cells consistently display an initial preference for the ventral path.

Once neural crest cells have entered the dorsolateral path, they progress rapidly to the distal edge of the somite. For example, at the level of the forelimb, the front of neural crest cells extends half way across the somite at stage 22 (4 days of incubation; Figs. 4C, 4D, 5) and reaches the distal edge of the somite by stage $23.5\left(4 \frac{1}{2}\right.$ days incubation; Fig. 7). Similarly at the level of the hindlimb, the crest cells traverse the width of the somite within a day (Figs. 3, 5, 7). At any axial level, the advance is fairly uniform across the dorsal face of the somite and exhibits no evidence of the segmental pattern that is typical of the ventral progression of crest cells through the anterior but not the posterior half of each segment (e.g., Rickmann et al., 1985).

Although migration is rapid and relatively homogeneous over the dorsal face of the dermatome, crest cells persistently delay their migration dorsal to the intersegmental boundaries. At each stage, crest cell progression dorsal to the intersomitic space lags behind the progression dorsal to either adjacent somite (Figs. 3, 5, 7). At stage 20 , few if any crest cells have invaded the path dorsal to the intersomitic space even at the forelimb level (Fig. 3). At stage 22, the most advanced crest cells dorsal to the dermatomes are half-way across each segment while the most advanced crest cells over the intersomitic space are only one-third of the way across the segment (Fig. 5). Even at stage 23.5, when some crest cells have migrated past the lateral edge of the somite, crest cells have advanced in the intersomitic regions to only half the width of the somites (Fig. 7).

Neural crest cells do not enter the ectoderm immediately after they enter the dorsolateral path. Instead, they are first found in the ectoderm at stage 22 at the

FIG. 1. Cross section through a stage 22 embryo that had been injected with DiI at stage 17 and then also labeled with HNK-1 after sectioning. (A) Low magnification showing intense HNK-1 labeling in the neural tube (NT), the sensory ganglion (G), and the precursors of the developing sympathetic (S) ganglion. Subectodermal label is barely perceptible at this magnification. (B) Higher magnification of HNK-1-labeled cells in the dorsolateral path. The $\mathrm{E}$ indicates the ectoderm in the identical spot in A and B. Five cells are clearly, but faintly, labeled (arrowheads 1-5). A sixth cell has faint perinuclear label (arrowhead 6). (C) Dil label of precisely the same region of the section viewed in B. Cells 1 and 3 are brightly labeled with DiI; cell 2 is not labeled; cells 4 and 5 are barely visible above background so that we cannot say with certainty if they have taken up the dye. Cell 6 is intensely stained with DiI in the perinuclear region, which is also labeled with HNK-1, and in a cell process, which is not labeled with HNK-1. M, myotome. Scale bar $=100 \mu \mathrm{m}(\mathrm{A}) ;=50 \mu \mathrm{m}(\mathrm{B}, \mathrm{C})$. 

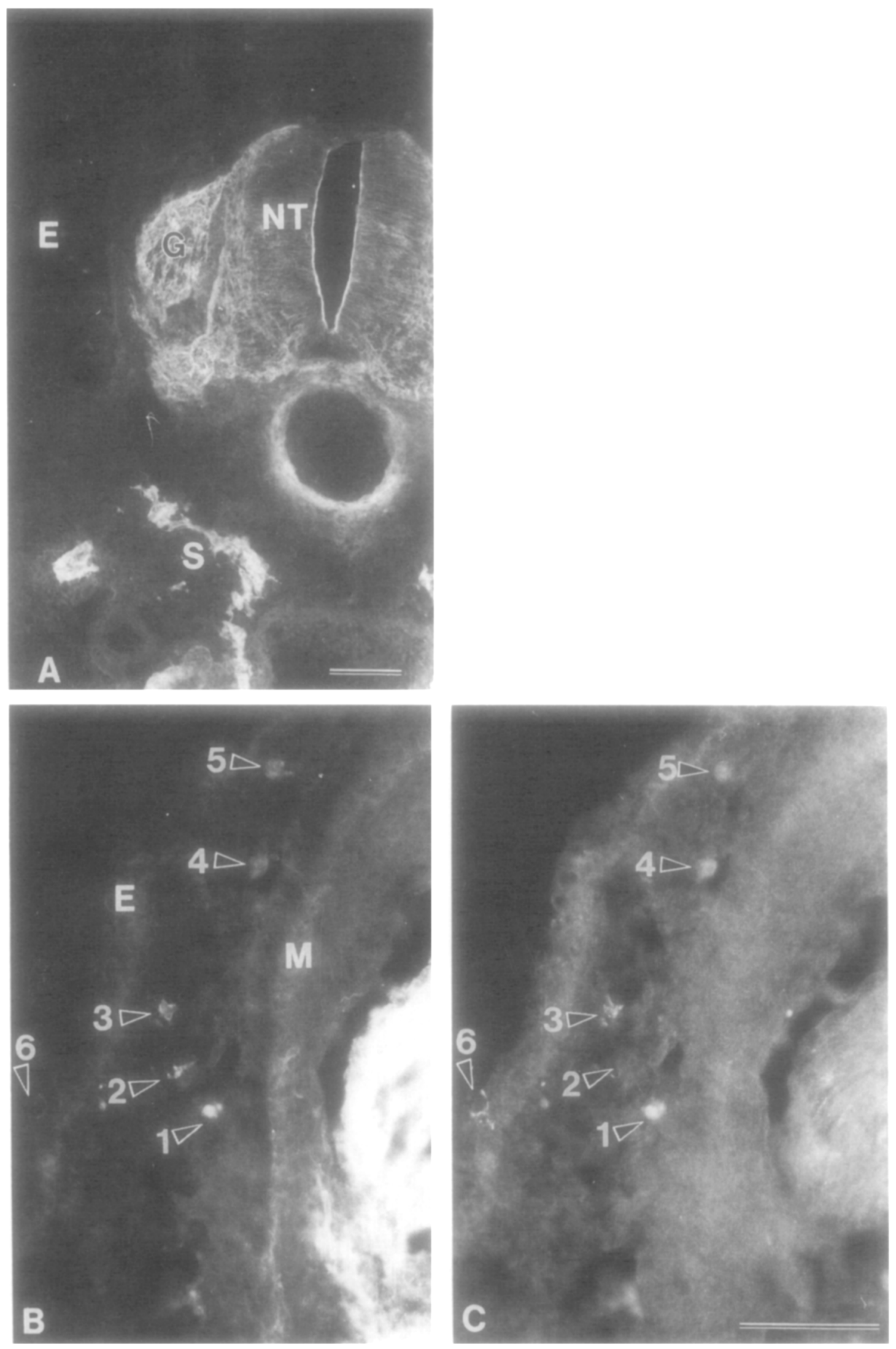
level of the forelimb (Fig. 5), two stages after cells first colonize the path. Crest cells first invade ectoderm at stereotyped sites; crest cells at the front of the migratory stream enter ectoderm that lies one-third to onehalf of the way distally along the dorsolateral path. By stage 23.5 crest cells have begun to massively invade the ectoderm (Fig. 6D), but only do so dorsal to the somites themselves; no crest cells are found in the ectoderm above the neural tube at any stage examined (e.g., Fig. 7).

\section{Relationship of Neural Crest Cells to Their Environment}

A major advantage of our preparation method is its enhanced preservation of embryonic cells which allows us to assess relationships between events in crest migration and events in somite morphogenesis. We were particularly interested in alterations that could explain the delay in entry into the dorsolateral path and the pattern of crest entry into the ectoderm.

The medial lip of the dermatome lies close to the ectoderm and could, in theory, present some sort of physical barrier. However, the medial dermatome and ectoderm are not tightly apposed; a small space that appears sufficient for cell passage is present between these tissues in our preparations. Moreover, the dimensions of this space do not alter markedly as neural crest cells enter the dorsolateral path. Except in embryos in which the ectoderm was displaced during preparation (e.g., Fig. $2 \mathrm{~B})$, the space between the medial dermatome and the ectoderm is similar in size before (Fig. 2A) and during (Fig. 4A) the ingress of neural crest cells. The delay in crest migration is therefore unlikely to be caused by simple physical constraints.

In addition, the medial dermatome does not alter in morphology as crest cells enter the path. Both before (Fig. 2B) and after (Fig. 2D) crest cell entry, the medial dermatome remains epithelial. In fact, the medial edge of the dermatome remains epithelial throughout the period studied, even up to stage 24 when some crest cells have progressed to the distal edge of the dorsolateral path (Fig. 6). The medial portion of the dermatome be- gins to disperse and form dermis at stage 26 at the hindlimb level (Tosney, unpublished observations), long after such dispersion could be relevant to crest colonization of the dorsolateral path.

However, the more lateral dermatome has just begun to lose its epithelial morphology and to form dermis at the stages when crest cells enter the dorsolateral path. Dermal cells first begin to disperse from the central portion of a dermatome, $80-100 \mu \mathrm{m}$ lateral to the medial lip of the dermatome. At the hindlimb level, these dermal cells first disperse at stage 20-21 (Tosney, unpublished results), coincident with neural crest entry into the dorsolateral path at this level. At stage 22, when crest cells have entered the dorsolateral paths at both fore- and hindlimb levels, dermal cells are clearly evident in the more distal regions of the dorsolateral path, near the mid-point of the dermatome (Figs. 4 and 14). By stage 24 at both fore- and hindlimb levels, the epithelial dermatome has completely lost its epithelial organization except at its medial lip, and dermal mesenchyme cells fill the dorsolateral path (Figs. 6 and 15). The formation of the dermal mesenchyme thus correlates with the entry and rapid migration of crest cells through the dorsolateral path.

Neural crest cells do not preferentially associate with any one cell type as they enter the dorsolateral path. The crest cells are initially restricted to a narrow region between the ectoderm and the dermatome where they frequently contact both surfaces simultaneously (e.g., Figs. 2A and 14C). In this site, contacts are not preferentially made with a single cell type even when the space is sufficiently wide so that a cell need only contact only one surface. For instance, at stage $20,48 \%$ of the cells were judged to contact dermatome, $25 \%$ were suspended in the extracellular matrix, and $27 \%$ contacted the ectoderm. Even at later stages (22-24), cells in the proximal portion of the path where dermal mesenchyme is absent contact ectoderm and dermatome equally often (e.g., Fig. 4D).

However, once crest cells have progressed distally into a region that contains dermal mesenchyme, they exhibit a preference for contact with this mesenchyme.

FIG. 2. Phase and immunofluorescence micrographs of stage 20 chick embryos that have been infiltrated with the HNK-1 antibody and sectioned at the level of the hindlimb $(A, B)$ and the forelimb $(C, D)$ establish that neural crest entry into the dorsolateral path is delayed relative to their entry into the ventral path. Ventral migration is well underway at both levels, as evidenced by the prominent sensory ganglion (S). At the level of the hindlimb, HNK-1-labeled cells (arrow in B) have collected in the cleft between the neural tube (NT) and the somite, but have not yet invaded the dorsolateral path. Note the small space between the medial lip of the dermatome and the ectoderm (arrows in A); the size of this space does not radically alter as crest cells invade the path (compare to Fig. 4A). At the level of the developmentally older forelimb (C, D), HNK-1-positive cells have spread past the medial edge of the dermatome and entered the dorsolateral path (arrow in D). Dermal cells (arrows in C) have begun to disperse from the more lateral dermatome coincident with the entry of the crest cells. This early dispersal of dermis is more clearly seen in Figs. 13 and 14. The ectoderm at this level has been artifactually lifted from the underlying tissues during fixation. M, myotome. Scale bar $=50 \mu \mathrm{m}$. 

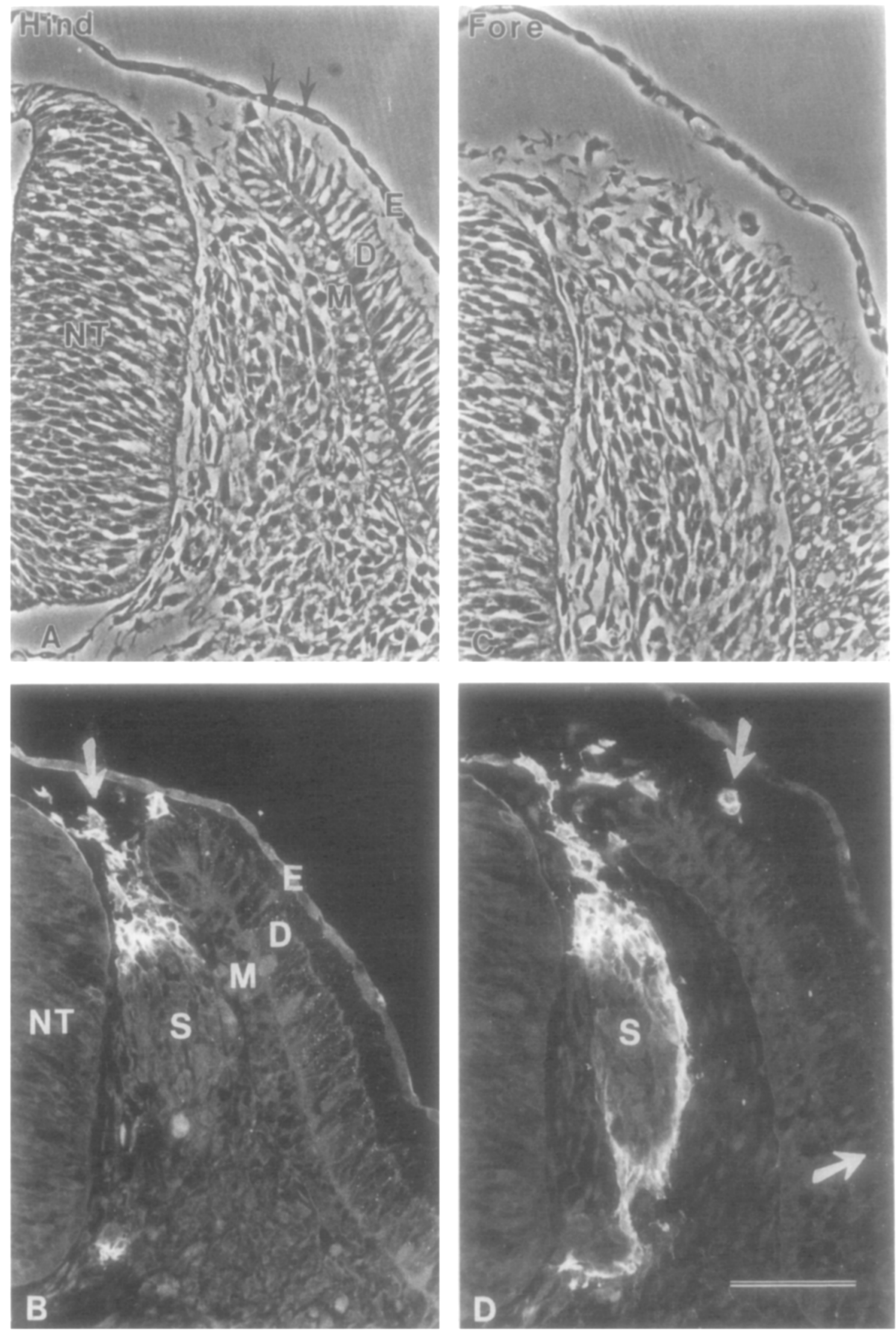

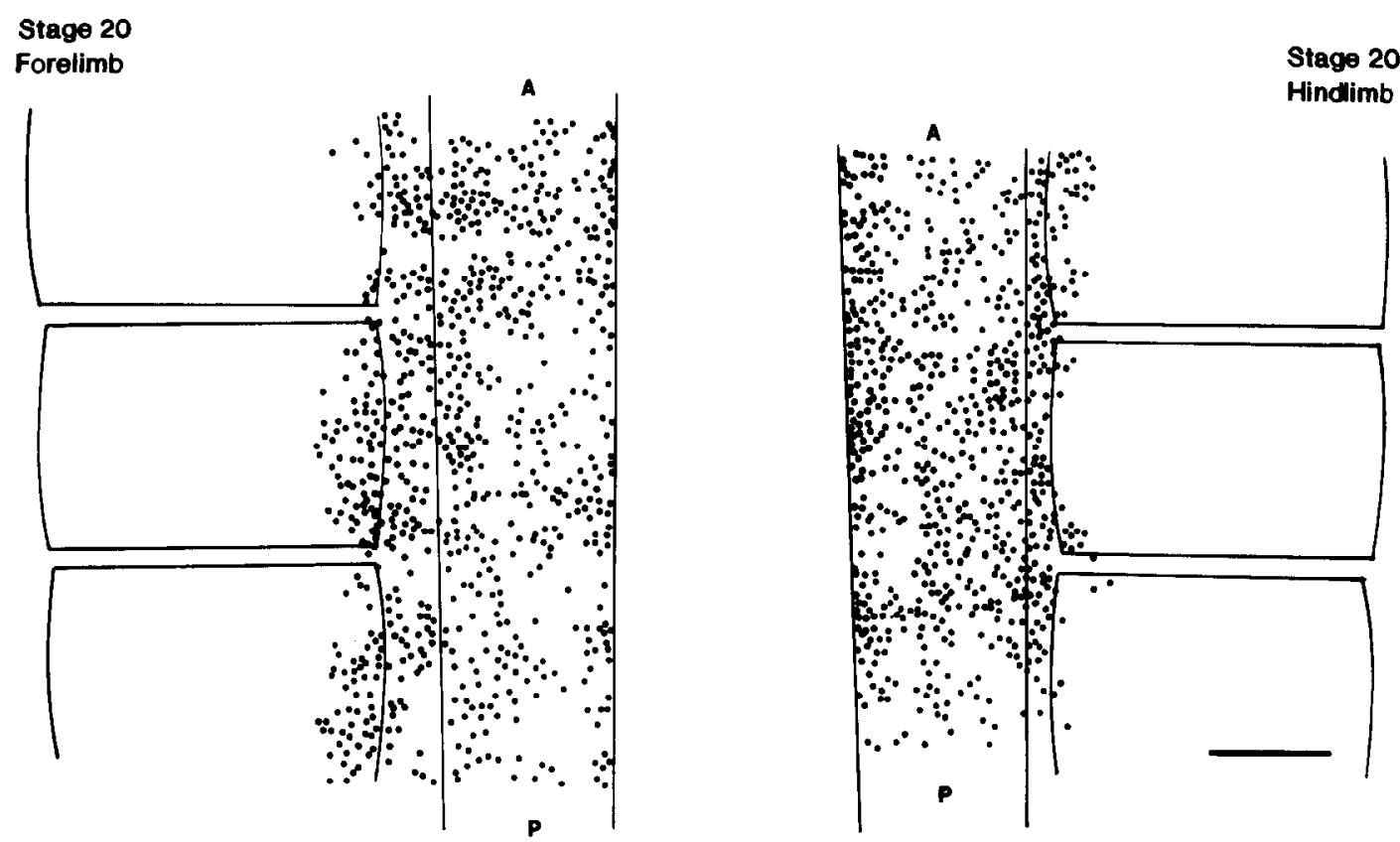

FIG. 3. Dorsal-view maps show the distribution of neural crest cells in the dorsolateral path in stage 20 embryos at the level of the forelimb and hindlimb. In this and subsequent maps, the neural tube and somites are outlined, neural crest cells in the dorsolateral path are represented by dots, anterior $(\Lambda)$ is oriented toward the top of the page, and the posterior $(P)$ is oriented toward the bottom of the page. At the forelimb level, neural crest cells have entered the dorsolateral path but have not progressed far in the region dorsal to the intersomitic space. Few crest cells have entered the dorsolateral path at the level of the developmentally younger hindlimb. Scale bar $=50 \mu \mathrm{m}$.

They seldom contact the ectoderm or the remaining epithelial portion of the dermatome in the distal regions of the path. By stage 22 , crest cells in the distal path are suspended in mesenchyme (Figs. 6, 14, 15).

The preference for contact with dermal mesenchyme may restrict the ability of crest cells to contact and enter ectoderm along the distal path and thereby determine the site where crest cells enter the ectoderm. The site where melanoblasts first enter ectoderm coincides with the proximal portion of the path where dermis is absent and crest cells remain in contact with the ectoderm (Fig. 5). Moreover, labeled cells that were frankly entering the ectoderm, because they were half-in and half-out, were seen only in the proximal half of the path.

To begin to address environmental features associated with neural crest invasion into the ectoderm, we photographed plastic sections that clearly showed HNK-1-labeled cells close to or part way into the ecto- derm (as in Fig. 6D) and then processed these sections for visualization with electron microscopy. Six labeled crest cells were relocated with the aid of the micrographs.

We consistently found that the basal lamina beneath the identified neural crest cell was gone, whereas the basal lamina was well developed and intact in adjacent areas (Fig. 8). Breaks in basal lamina unassociated with crest cells were very rare. In particular, an association between unlabeled mesenchyme cells and ectoderm was not sufficient to disrupt the basal lamina. Unlabeled mesenchyme cells, which we presume to be dermal cells, were often close to the ectodermal undersurface and yet the basal lamina was never disrupted at these sites. Thus disruptions in the basal lamina correlate with a close association between neural crest cells and the undersurface of the ectoderm. Therefore, a local dissolution of the basal lamina, possibly initiated by the crest

FIG. 4. Matched phase and immunofluorescence micrographs show sections through the level of the hindlimb (A, B) and forelimb (C, D) of a stage 22 embryo. By this stage neural crest cells have begun to rapidly colonize the dorsolateral path at both axial levels. In $\mathrm{B}$, labeled cells (arrowheads) are in close contact with the dermatome in the proximal region of the path at the hindlimb level; in adjacent sections, labeled cells also spread on the ectodermal undersurface. Dermal mesenchyme cells (e.g., arrowheads in A) have begun to accumulate in the more lateral portions of the path (also see Fig. 14). In D, crest cells have progressed far laterally and are often spread on the surface of the ectoderm (e.g., arrowhead) and dermatome (e.g., double arrowhead). Note that all the cells that can be seen in the medial portion of the dorsolateral path in $\mathrm{A}$ and $\mathrm{C}$ are also labeled with HNK-1 in $\mathrm{B}$ and D; only neural crest cells are expected to lie in this region, confirming the sensitivity of the HNK-1 antibody in our preparations. E, ectoderm; D, dermatome; M, myotome; NT, neural tube. Scale bar $=50 \mu \mathrm{m}$. 

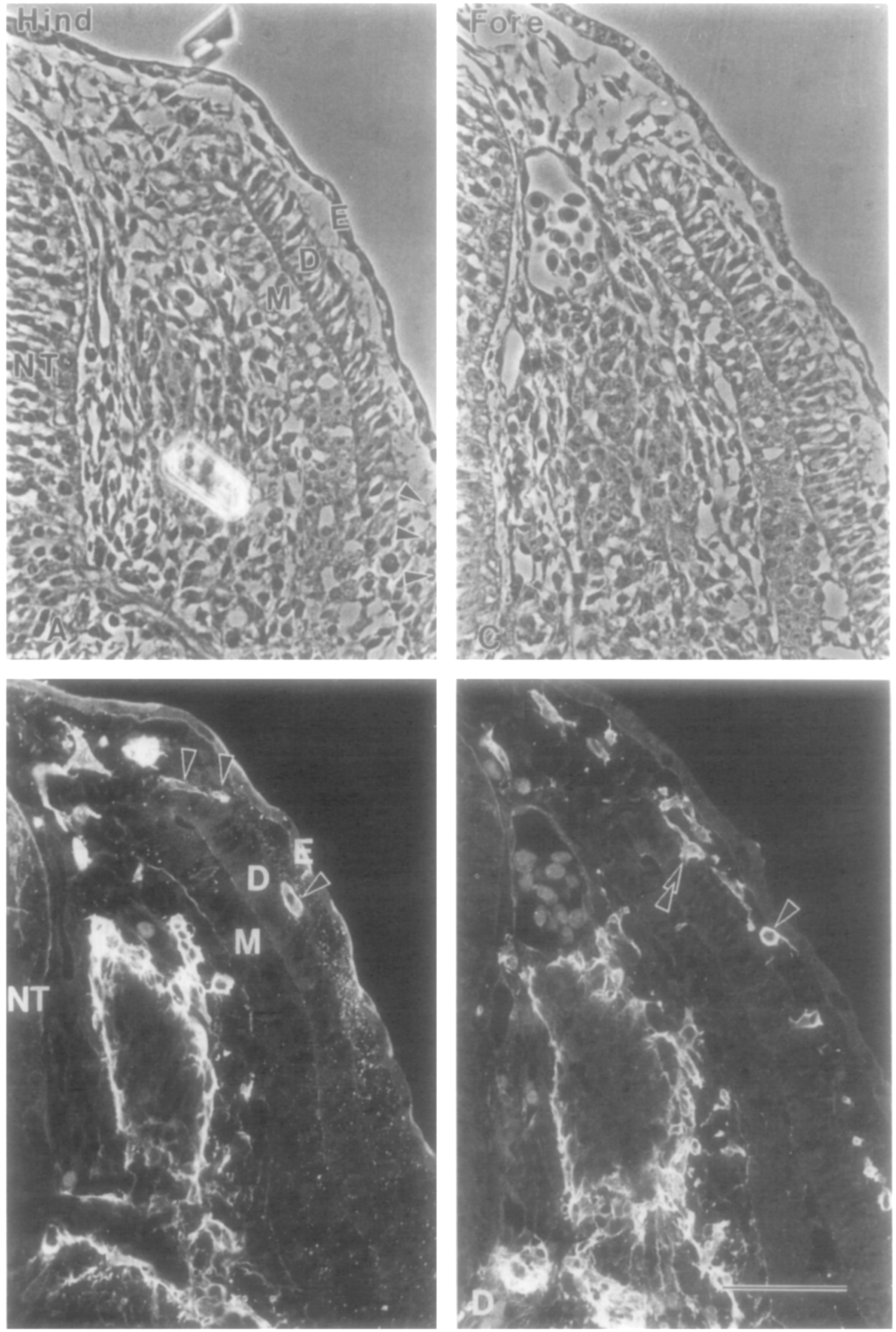

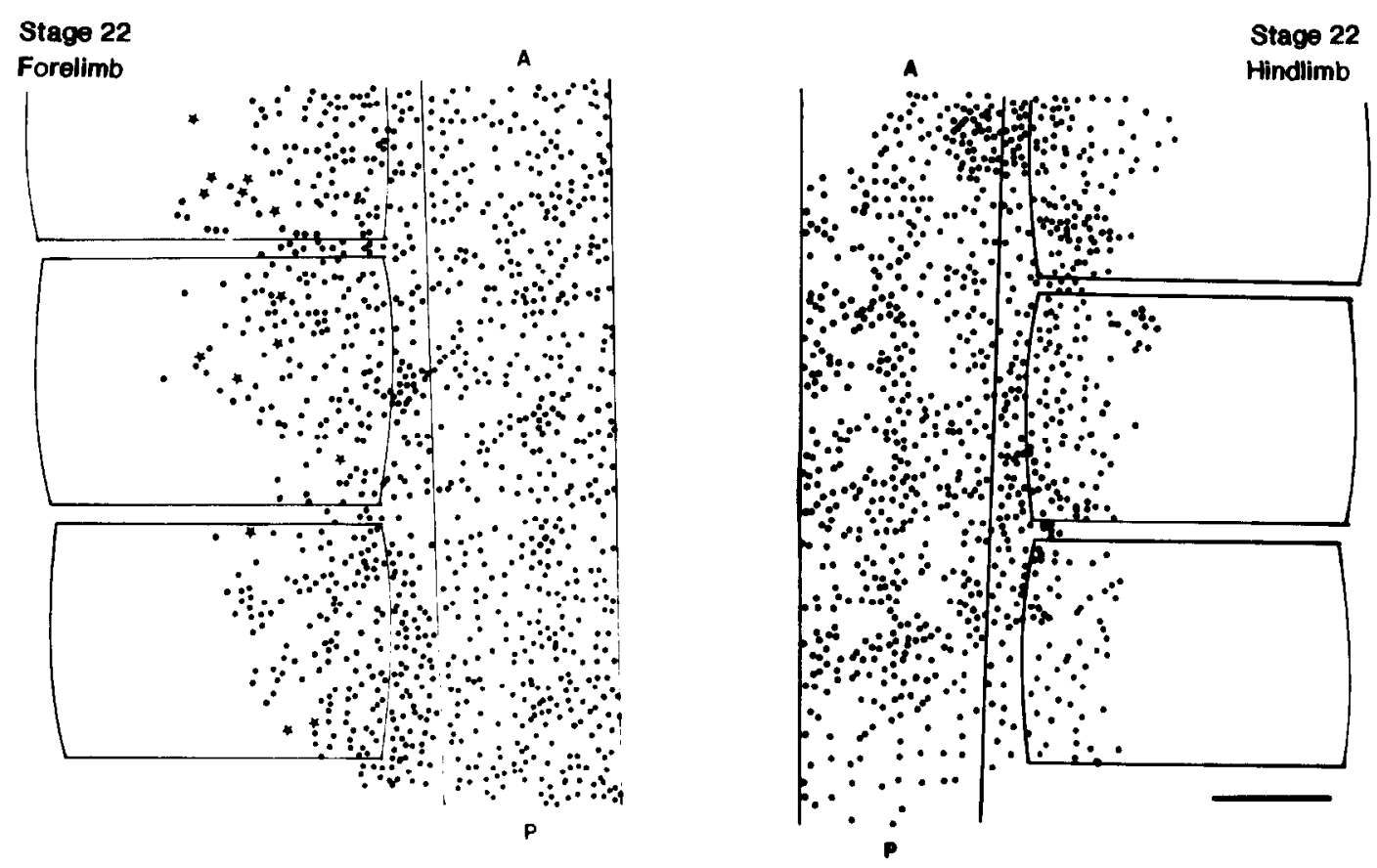

Fig. 5. Dorsal-view maps show the distribution of neural crest cells in the dorsolateral path in a stage 22 embryo at the levels of the forelimb and hindlimb. Crest cells have rapidly advanced to near the middle of the somites at both levels and some cells have invaded the ectoderm (represented by stars) at the forelimb level. Note that crest migration is considerably delayed dorsal to the intersomitic space compared to migration dorsal to the somite. A, anterior; P, posterior. Scale bar $=50 \mu \mathrm{m}$.

cells themselves, may be essential for crest cells to enter the ectoderm.

\section{Crest Cells Enter Precociously When the Dermamyotome Is Deleted}

An obvious candidate to control the time of ingress into the dorsolateral path is the dermatome. The dermatome cannot be selectively removed, but the precursor of both the dermatome and the myotome, the dermamyotome, can be deleted before neural crest cells emigrate from the neural tube. We deleted dermamyotomes at hindlimb levels at stage 17 and fixed the embryos from stage 20 , before neural crest cells normally enter the dorsolateral path at this level, through stage 26, when crest cells have normally completed their migration through this path.

Deletion of the dermamyotome consistently accelerates crest cell entry into the dorsolateral path. In the map of a stage 20 embryo shown in Fig. 9, few crest cells have entered the dorsolateral path on the control side, but crest cells have clearly begun to proceed into the path on the operated side. Premature migration is even more apparent when the operated embryos are fixed only a stage or two later (stage 21 , Figs. 10 and 13; stage 22, Figs. 11 and 14). At these stages, crest cells have only just begun to invade the dorsolateral path on the control side, whereas on the operated side, crest cells are dispersed almost half-way along the width of the somite. Once crest cells gain access to this path, they colonize it rapidly.

The migratory advantage conferred by a dermamyotome deletion does not persist throughout the period of migration. By stage 23.5 the neural crest cells on the control side have dispersed as far distally as those on the operated side; they have nearly reached the distal edge of the somite (Figs. 12 and 15) and thus appear to have caught up with their prematurely migrating sis-

FIG. 6. Matched phase and fluorescence micrographs show sections through the hindlimb (A, B) and forelimb (C, D) of a stage 24 chick embryo. Crest cell migration has nearly reached the distal edge of the somites at both levels (arrowheads in B and D) and some of the labeled cells are partially or entirely in the ectoderm (double arrowheads in D). The medial tip of the dermatome (arrowhead in $A$ and C) remains epithelial even at this late stage, whereas abundant mesenchyme cells (double arrowheads in A and C) have detached from the more lateral dermatome. Crest cells have spread among these mesenchyme cells and fewer crest cells are in close contact with the ectoderm than at the previous stage. Scale bars $=50 \mu \mathrm{m}$. 

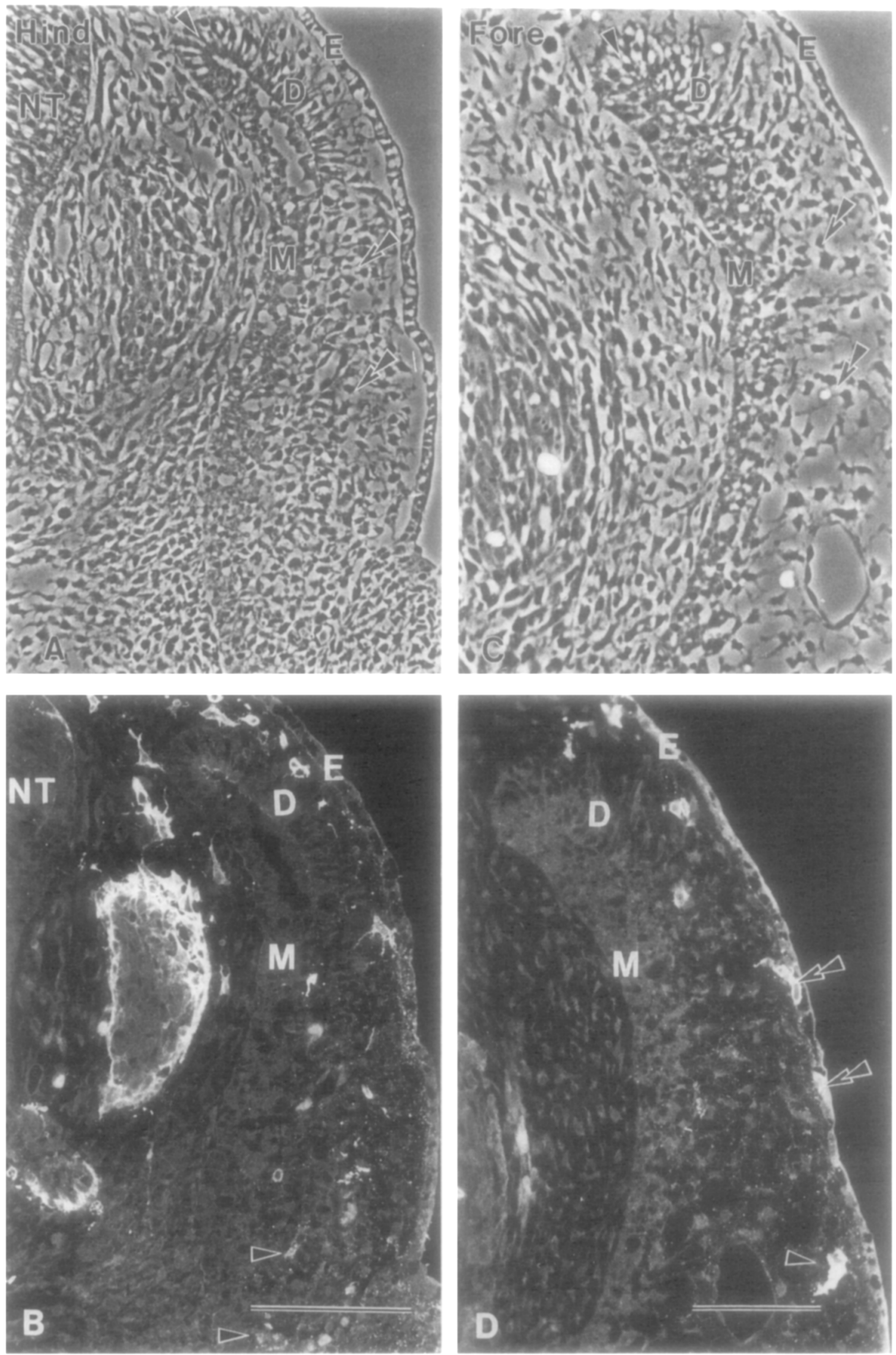


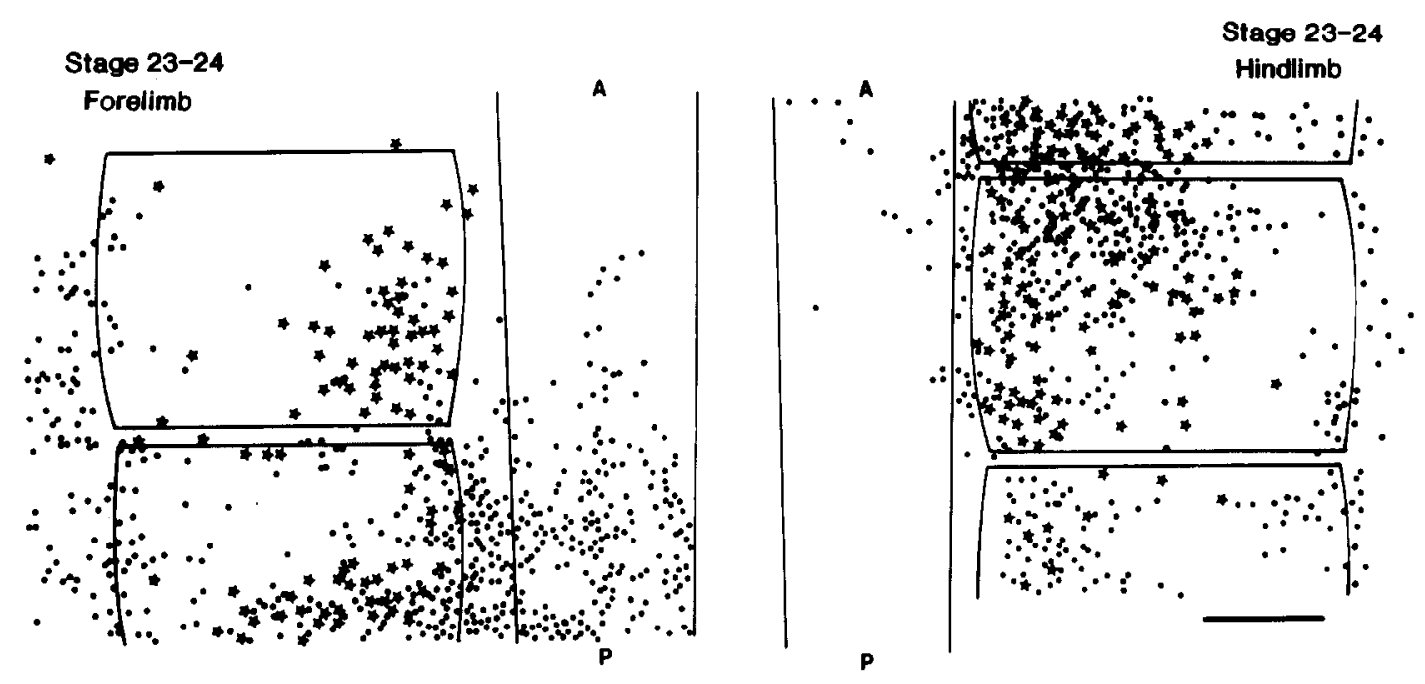

FIG. 7. Dorsal-view maps show the distribution of HNK-1-labeled cells in a stage 23.5 embryo at the level of the forelimb and hindlimb. Labeled cells have spread beyond the distal edge of the somites and have heavily infiltrated the ectoderm (stars) but migration is still delayed dorsal to the intersegmental boundaries. Scale bar $=50 \mu \mathrm{m}$.

ters. Even the local absence of lateral dermatome does not further enhance distal migration at this stage.

The entire dermatome need not be absent for precocious migration. In fact, in the stage 21 embryo shown in Fig. 10 in which three contiguous dermamyotomes have been partially removed, crest cells have migrated to equivalent distal extents in the central segment, which has virtually no dermatome, and in the adjacent segments in which large portions of dermatome remain. It is also clear that the epithelial dermatome is not absolutely inhibitory to crest migration, since crest cells lie dorsal to islands of dermatome in most operated segments (Figs. 9 to 15).

Although ventral and dorsal paths are contiguous in the absence of the intervening dermatome and myotome, we are certain that these crest cells are migrating precociously along the dorsolateral path and are not within the ventral path. If these crest cells were in the ventral path, we would expect to see them only in the anterior half of a segment, and we do not. In both the anterior (Figs. 14 and 15) and the posterior (Fig. 13) portions of operated segments, crest cells are obviously advancing distally through a similar dorsal region, within two to three cell diameters of the ectoderm. In fact, the number of crest cells does not obviously differ in the anterior and posterior halves of the dorsolateral path; crest cells spread homogeneously through the path following deletions (Figs. 10,11,12).

Despite the precocious entry of neural crest cells into the dorsolateral path when the dermamyotome is deleted, neural crest cells do not enter the ectoderm prematurely; instead, their entry into the ectoderm is delayed.
The first crest cells normally enter the ectoderm at the hindlimb level by stage 23 , when the leading front of cells has reached the mid-somite level (Fig. 7). The most advanced crest cells have reached comparable positions on the operated side of the stage 22 embryo shown in Fig. 11, but none of these cells have entered the ectoderm. Similarly, crest cells have yet to enter the ectoderm on the operated side in the stage 23 embryo shown in Fig. 12, despite the fact that crest cells have nearly reached the distal edges of the somites, and despite the fact that several crest cells have entered ectoderm on the control side. Although the number of crest cells that normally enter the ectoderm before stage 24 is small, the consistent absence of crest cells in the ectoderm on operated sides suggests that the operation has in some way delayed crest cell entry into the ectoderm.

\section{Relationship of Neural Crest Cells to Their Environment after Dermamyotome Deletion}

One of the more dramatic alterations in the environment following dermamyotome deletions is an enlarged spatial distribution of unlabeled mesenchyme cells. For instance, and in contrast with the normal absence of dermal mesenchyme at the entrance to the dorsolateral path, mesenchyme cells are abundant at the entry to the path when the medial dermatome is absent (Fig. 13). This mesenchyme often extends five to six cell diameters ventrally and gradually merges with the more densely packed ventral mesenchyme that presumably represents sclerotome. Mesenchyme can fill in even 

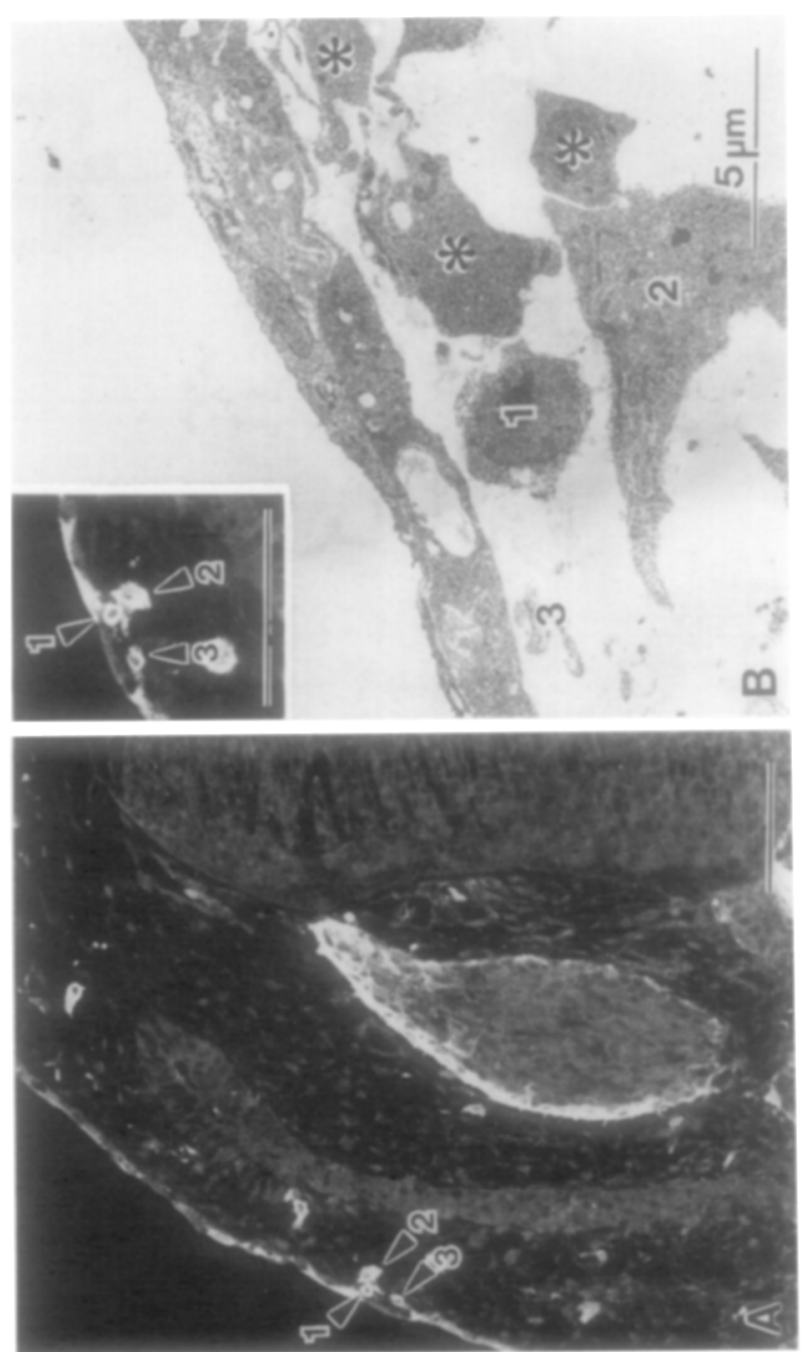

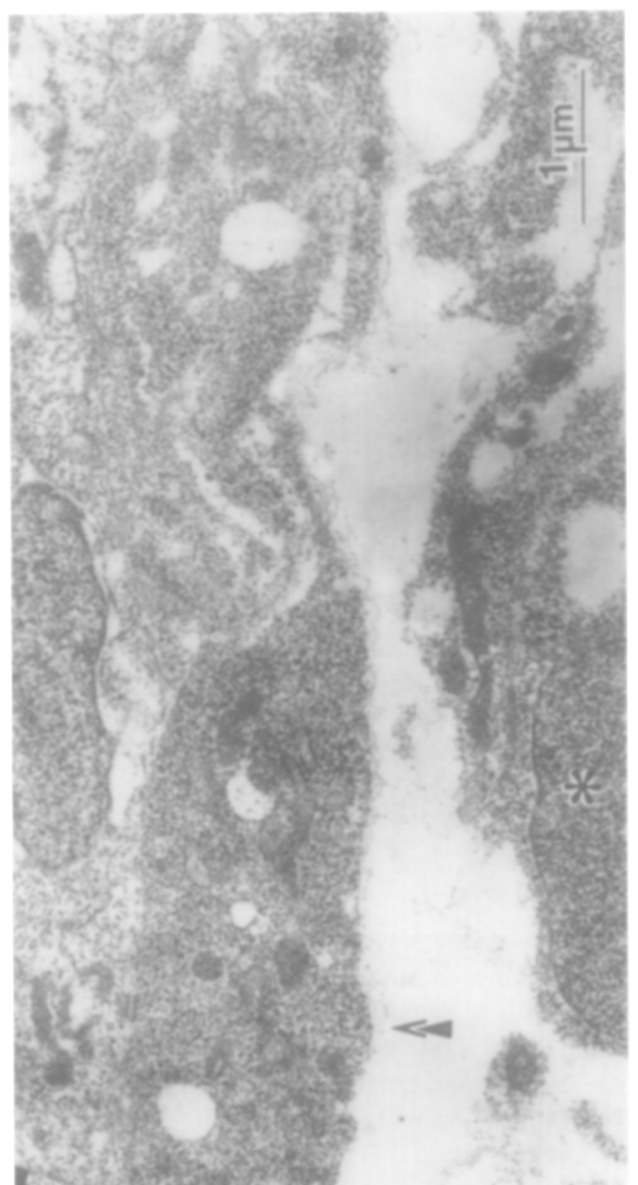

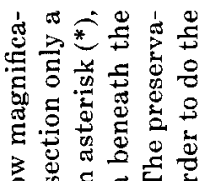

है वै

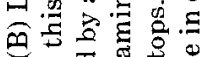

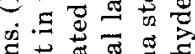

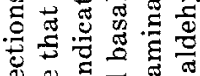

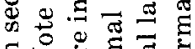

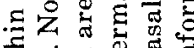
实 5 政

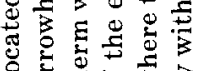
원

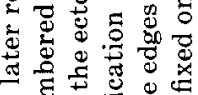

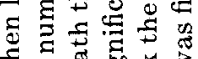
궁

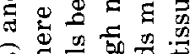

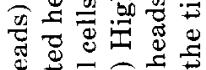
苞焉可产

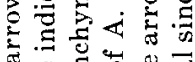

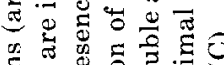

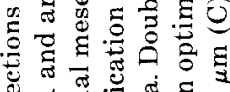
แ

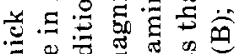

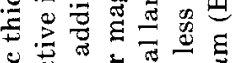

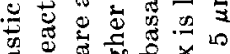

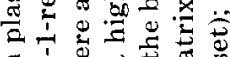

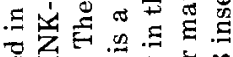

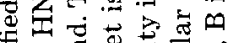

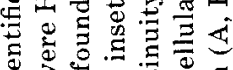
要这政

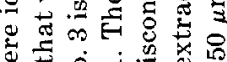

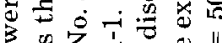

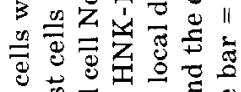

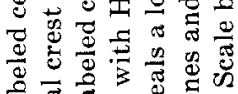
元要

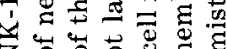
乙讨

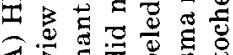

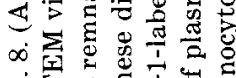

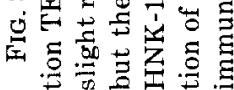




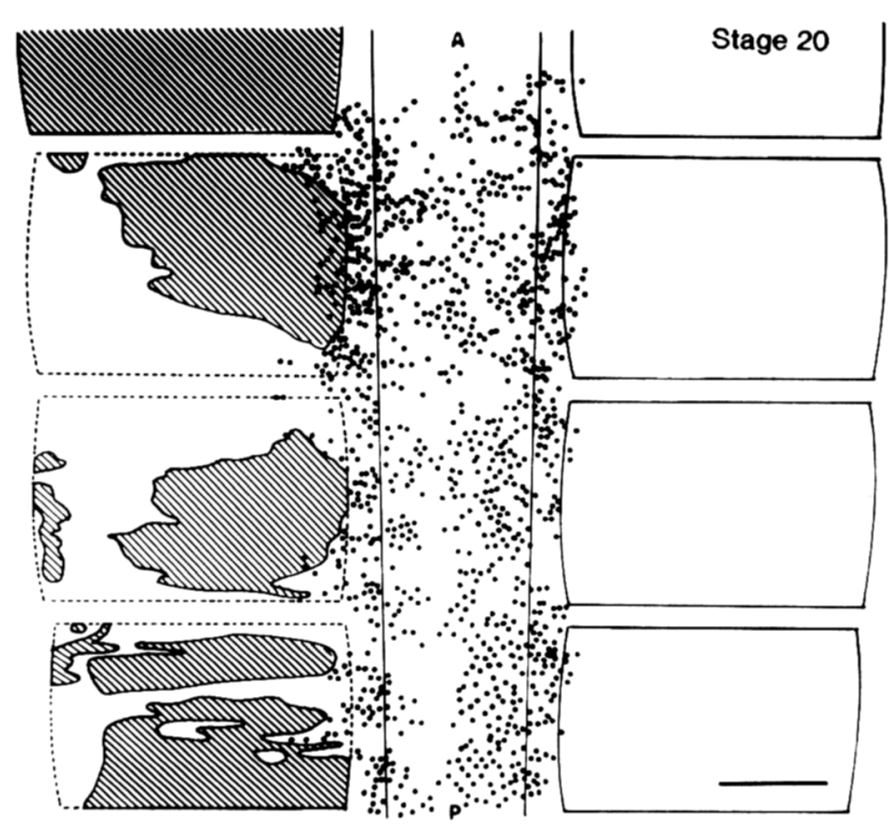

FIG. 9. A dorsal-view map shows a stage 20 embryo, which had portions of three dermamyotomes removed at stage 17 . Remnants of the dermatome are represented in this and subsequent maps by diagonal lines. On the unoperated side (right), few neural crest cells have entered the dorsolateral path. In contrast, crest cells have begun to invade the dorsolateral path in those segments where the dermatomes are depleted. Scale bar $=50 \mu \mathrm{m}$.

when the dermatome is partially intact. Following partial dermatome deletion, mesenchyme spreads over the remaining dermatome (Figs. 14 and 15). Thus even after partial deletions, the entire dorsolateral path is often filled with mesenchyme.

In concert with the wider swath of mesenchyme cells, crest cells also extend farther ventrally, rather than forming a narrow stream adjacent to the ectoderm. For instance, in an operated embryo at stage 21, crest cells on the operated side are dispersed in mesenchyme at least three cell widths deep beneath the ectoderm (Fig. 13A). The wider band of unlabeled mesenchyme cells following dermamyotome deletions and the consequent deeper distribution of crest cells persist in later developmental stages.

Because crest cells are more dispersed in mesenchyme, few if any crest cells are closely associated with the ectodermal surface following dermamyotome deletion (compare normal and operated stage 24 embryos in Figs. 6D and 15A). Crest cells may enter the ectoderm on the operated side less frequently than normal not because the deletion of the dermamyotome has removed something essential to their entrance into the ectoderm, but because fewer crest cells directly contact the ectoderm.

\section{DISCUSSION}

This paper describes the pattern of dispersion of putative neural crest cells labeled with the HNK-1 antibody along the dorsolateral path in the trunk of chick embryo. We show that the HNK-1 antibody, which has been assumed not to label premelanocytes, does label neural crest cells in the dorsolateral path and in the ectoderm. Moreover, this antibody reveals a consistent pattern of colonization of the dorsolateral path. The progression of crest cells along this path has not previously been documented in detail. Our study next addresses three issues concerning the control of this migration. First, we confirm that crest cells delay entering the dorsolateral path until a day or more after their counterparts have colonized the ventral path. Second, we show that the invasion of crest cells into the ectoderm coincides with local disruptions in the basal lamina. Third, we demonstrate that the delay in entry of the neural crest cells into the dorsolateral path is reduced by the prior deletion of the dermamyotome and we provide de-

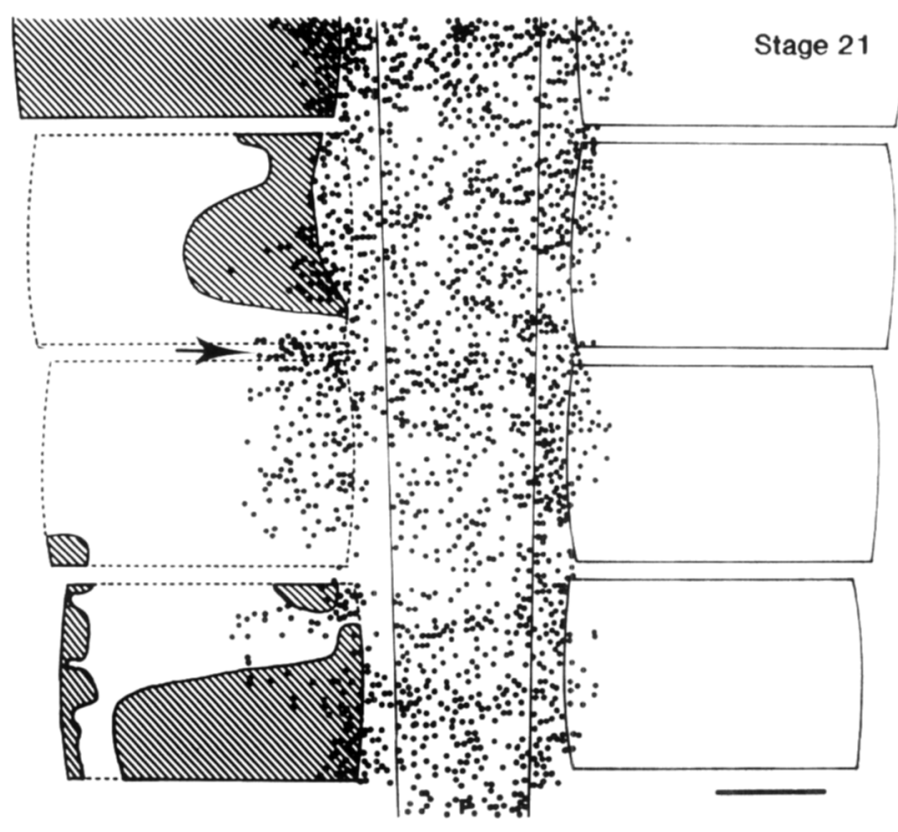

Fig. 10. A dorsal-view map shows a stage 21 embryo, which had portions of three dermamyotomes removed at stage 17 . Crest cells are just beginning to invade the dorsolateral path on the normal (right) side. In contrast, crest cells have deeply penetrated the dorsolateral path on the left side where the dermatomes are largely absent. The extent of precocious migration is not directly related to the size of the deletion. Crest cells have penetrated as far distally in the central segment, in which the dermatome is virtually absent, and in the adjacent segments that retain large remnants of dermatome. Note that crest cells have also precociously migrated dorsal to the intersegmental space at the site where dermatomes are absent on both sides of the intersegmental space (arrow). Scale bar $=50 \mu \mathrm{m}$. 


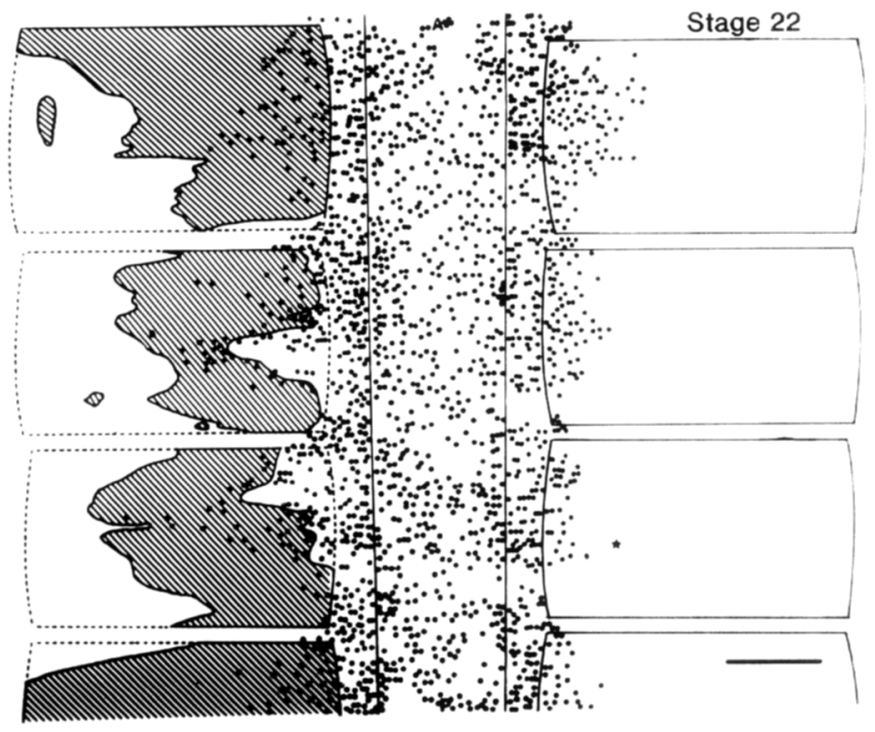

Fig. 11. Dorsal-view map shows a stage 22 embryo, which had portions of three dermamyotomes removed at stage 17 . As in the previous figures, crest cells spread rapidly into the dorsolateral path when the dermatome is even partially absent. The removal of the dermamyutome that borders only one side of an intersomitic space does not detectably enhance crest migration dorsal to this region. Seale bar $=$ $50 \mu \mathrm{m}$.

scriptive and experimental evidence that the dermatome controls neural crest access to the dorsolateral path.

\section{Are These HNK-1-Labeled Cells Neural Crest Cells?}

Five observations convince us that cells in the dorsolateral path that are labeled with HNK-1 are indeed neural crest cells. First, HNK-1 labels cells within and entering the ectoderm; these cells must be melanoblasts since pigment cells are the only cell type known to invade the ectoderm. Second, HNK-1-positive cells in the dorsolateral path form a continuous stream with the HNK-1-positive cells emanating from the dorsal neural tube, which are by definition neural crest cells. Third, at the early stages when dermal mesenchyme cells are only beginning to disperse from the lateral dermatome, all of the cells in the medial portion of the dorsolateral path label with the antibody; only neural crest cells would be expected in this region. Fourth, cells in the dorsolateral path that are identified as crest cells by the prior injection of DiI into the neural tube also label with HNK-1. Finally, the times when HNK-1-labeled cells invade the dorsolateral path and the ectoderm in our study are consistent with the times inferred in two previous studies that used different techniques. Fox (1949) deduced when crest cells enter ectoderm by asking when isolated pieces of ectoderm could generate melanocytes. If we assume these ectodermal pieces were contaminated by adherent dermis and therefore show when melanoblasts enter the path rather than the ectoderm, our results are consistent with hers: neural crest cells invade the dorsolateral path at the forelimb at stage 20 and at the hindlimb at stage 21. Likewise, although Teillet (1971) did not specify axial levels or embryonic stages, her results using quail-chick chimeras are also consistent with ours.

Two reasons may plausibly explain why HNK-1 was not previously recognized to label crest cells in the dorsolateral path. First, many studies of neural crest cell migration using this antibody have stopped short of analyzing stages where invasion into the dorsolateral path begins (e.g., Rickmann et al., 1985; Loring and Erickson, 1987). In these studies, the absence of label in the dorsolateral path was due to an absence of migrating cells, not to an absence of antigenicity in the premelanocytes. Second, applying the antibody to sections appears to stain the dorsal subpopulation of crest cells less effectively than incubating embryos in the antibody for $24 \mathrm{hr}$ prior to embedding. The long incubation time may increase antibody binding or the epitope may be lost during paraffin embedding (see also Bronner-Fraser, 1986). We conclude that HNK-1 is a useful marker for studying the migration of neural crest cell into the dorsolateral path using our techniques.

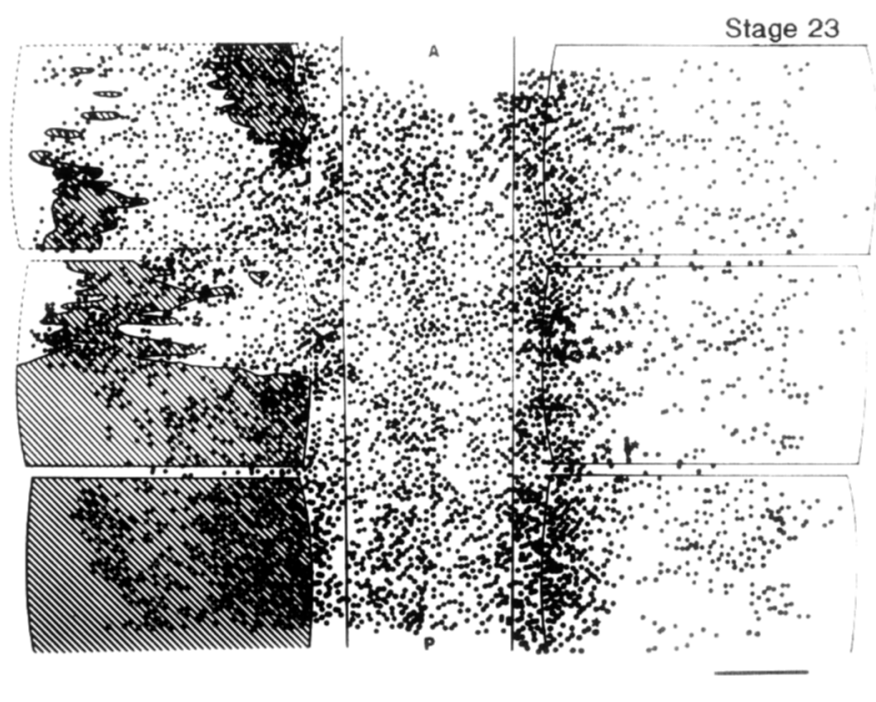

FIG. 12. Dorsal-view map shows a stage 23 embryo, which had portions of two dermamyotomes removed at stage 17. By this stage crest cells have reached equivalent distal positions along the dorsolateral path on the normal and the operated sides. While crest cells have begun to invade the ectoderm on the control side (stars), crest cells have yet to invade the ectoderm on the operated side. Migration dorsal to the intersomitic space still lags behind migration dorsal to the somite on both sides. Scale bar $=50 \mu \mathrm{m}$. 

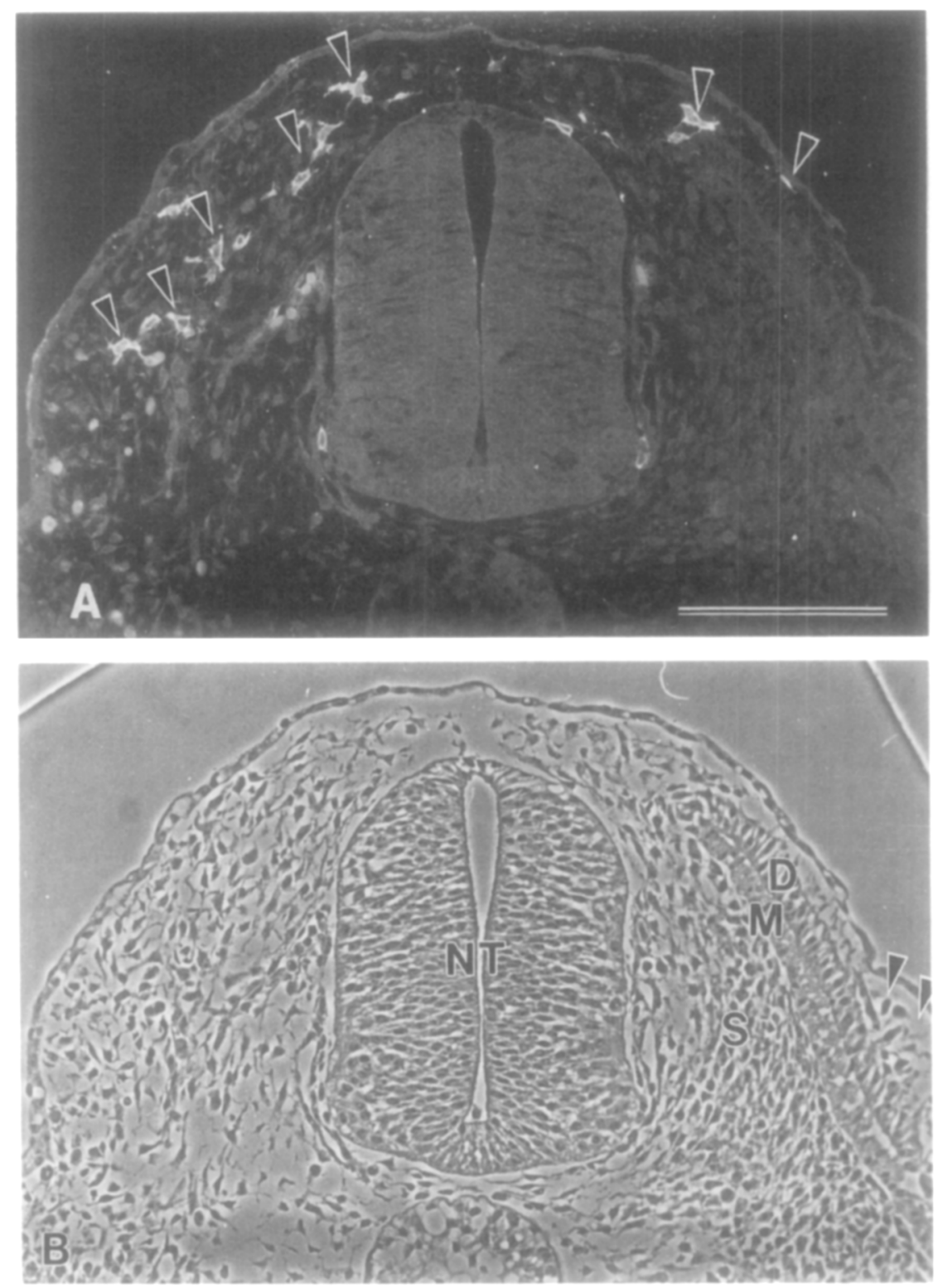

FIG. 13. Matched fluorescent (A) and phase (B) micrographs of a cross section through the stage 21 embryo mapped in Fig. 10 shows the segment with the most complete dermamyotome deletion. Crest cells are not expected to be present in the ventral path because this section is through the posterior of the segment. On the control side (right) crest cells have just begun to invade the dorsolateral pathway (arrowheads in A) and the dermis is dispersing from the more lateral dermatome (arrowheads in B). In contrast, in the absence of the dermatome on the operated side (left), crest cells (arrowheads in A) have migrated far distally and are not confined to a narrow region adjacent to the ectoderm. These crest cells are dispersed in a loose mesenchyme (B), which fills the dorsolateral path on the operated side. Scale bar $=100 \mu \mathrm{m}$.

\section{Timing and Pattern of Migration in the Dorsolateral Path}

Our descriptive analysis of neural crest migration in the dorsolateral path documents in unprecedented detail the temporal and spatial patterns of this migration. We show that crest cells migrate into the dorsolateral path in an anterior to posterior wave and we document the times and positions of crest cell advance at fore- and hindlimb levels. We confirm that the distribution of neural crest cells over the somites is relatively uniform, unlike the restriction of crest cells along the ventral path to the anterior half of the somite (see also Serbedzija et al., 1989). In addition, we show for the first time that migration is also delayed dorsal to the intersomitic space, imposing a subtle and transient segmental distribution on the pattern of crest cell dispersion in this path. 
We also characterize in detail a delay in crest cell entry into the dorsolateral path. For instance, at the hindlimb level, crest cells emigrate from the neural tube and enter the ventral path by early stage 18 (cf, Loring and Erickson, 1987; Tosney, 1988) and yet the first crest cells enter the dorsolateral path at stage 21 , a delay of a day. These results confirm and extend the results of others (e.g., Teillet, 1971; Mayer and Oddis, 1977; Derby, 1978; Serbedzija et al., 1989). We also establish that once crest cells enter, they colonize the path quite rapidly. This work strongly suggests that some environmental feature restricts access to the dorsolateral path until late periods of neural crest emigration.

\section{Control of Invasion into the Ectoderm}

We also address the here-to-fore unexplored problem of how pigment cells get into the ectoderm. Entrance in to the ectoderm is a problem because the basal lamina is widely suspected to be a barrier to cell invasion, and at Day 4, when we have shown that crest cells invade the ectoderm, the basal lamina under the ectoderm is largely continuous. A previous study has shown that neural crest cells do not invade an intact embryonic basal lamina (Erickson, 1987). Likewise, Gehlsen et al. (1984) and Gehlsen and Hendrix (1987) have demonstrated that neural crest cells will not penetrate a basal lamina isolated from placental amnions. However, melanoblasts may be more invasive than the newly migrating neural crest cells used in the above studies. For instance, pigment cells injected into chicken blood vessels will home to the ectoderm and presumably must invade through the basal lamina (Weiss and Andres, 1952; Cudennec, 1977). We therefore focused on the condition of the ectodermal basal lamina just prior to and during the invasion of neural crest cells.

We document that local breaks in the basal lamina are confined to positions adjacent to neural crest cells. This concordance suggests that the melanoblasts are degrading the basal lamina prior to their penetration. Had these cells invaded by forcefully boring their way through the basal lamina, we would have expected to see intact basal lamina up to the edge of the neural crest cells as they invaded the epidermis, and we would not expect to find a break in the basal lamina prior to invasion. Instead we find large expanses of basal laminafree areas underneath the cells.

Other evidence also suggests that these neural crest cells can actively degrade basal lamina. In previous studies we and others (Valinsky and Le Douarin, 1985; Erickson and Isseroff, 1989; Menoud et al., 1989) have shown that neural crest cells produce plasminogen activator, which not only converts plasminogen to the pro- tease plasmin, but can by itself degrade components of the extracellular matrix (Fairbairn et al., 1985; Quigley et al., 1987). Moreover, the activity of this enzyme appears to increase with the time neural crest cells are engaged in motile activity in culture. We previously speculated that neural crest cells are stimulated to produce proteolytic enzymes such as plasminogen activator as they migrate (Erickson and Isseroff, 1989). Melanoblasts may require a day or two of active migration in the embryo before they can produce sufficient levels of protease to breach the basal lamina barrier. Certainly, the first cells to invade the ectoderm are at the leading edge of the migratory front and have migrated farthest. In contrast, crest cells that still lie dorsal to the neural tube have not migrated far and have yet to enter the adjacent ectoderm. In operated embryos, crest cells that have migrated extensively may fail to precociously enter ectoderm because they have spread ventrally among dermal cells, precluding a direct interaction with the ectoderm.

\section{Control of Entry into the Dorsolateral Path}

We can subtly but consistently accelerate the entry of crest cells into the dorsolateral path. Following partial deletions of dermamyotomes at the hindlimb level, crest cells enter this path at stage 20 and proceed rapidly to the midpoint of the somite by stage 22 , well in advance of their counterparts on the unoperated side. The acceleration in entry is not consistent with the supposition that some crest cells are predetermined melanocytes that enter this path on an innate timetable. The experimental results thus establish that the path itself is transiently inhibitory.

Both our descriptive and our experimental results further implicate the dermatome in the early inhibition. The dermatome is likely to transiently restrict access to the early dorsolateral path. However, the most obvious scenario, that the medial edge of the dermatome closely abuts the ectoderm and thus acts as a physical barrier to migration, is not supported by our work. These tissues are not closely apposed before the entry of crest cells and, while the space between the tissues is small, the space does not obviously enlarge as crest cells enter the path. This space is unlikely to be an artifact of fixation since Newgreen (1989) also reported a space in this region in unfixed embryonic tissue. There are, therefore, no obvious grounds for a physical exclusion of crest cells. 'The molecular and/or cellular composition of the dorsolateral path is more likely to control the time of crest cell entry.

Several plausible explanations remain for the control of crest cell migration into the normal dorsolateral path 

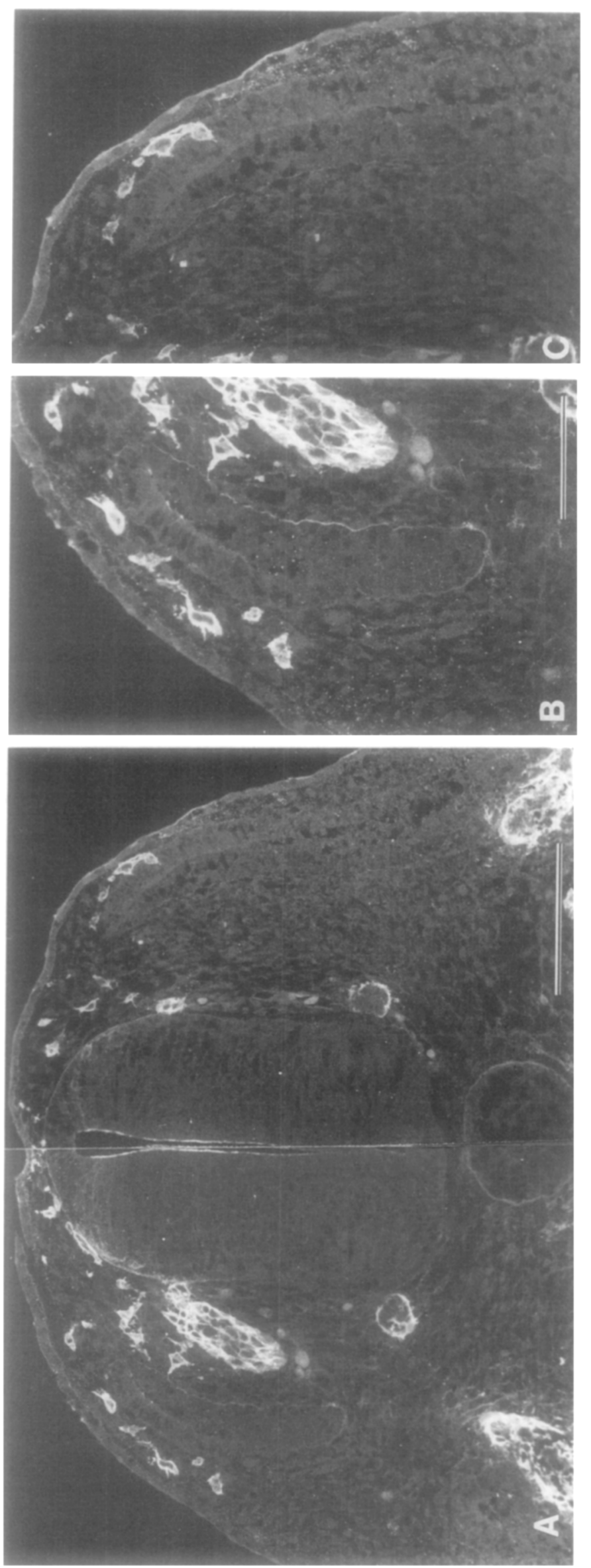

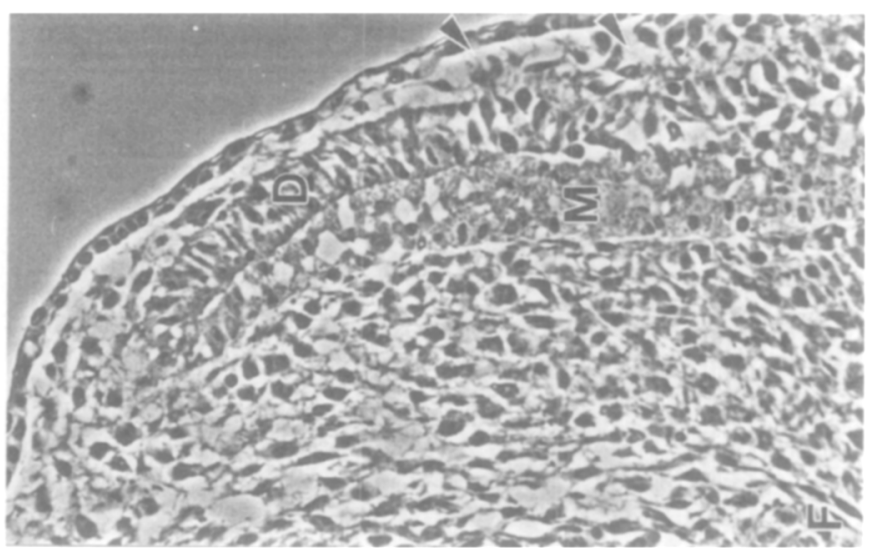

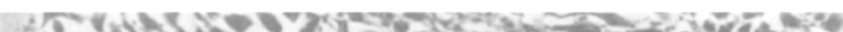

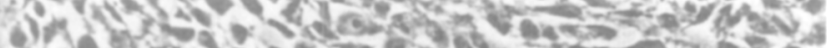

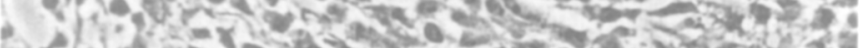

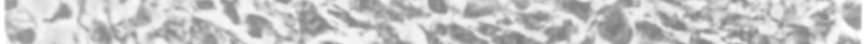

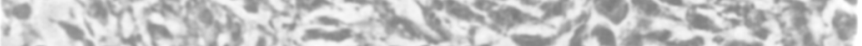

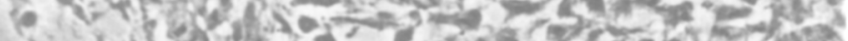

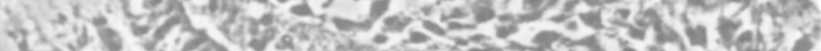
2. te

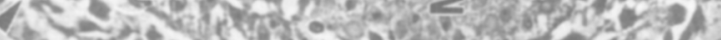

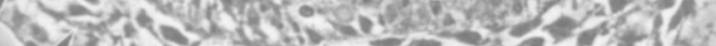

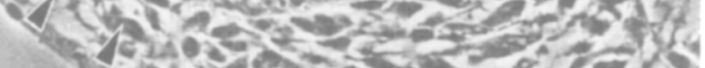
Teia

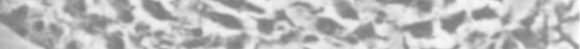
- of

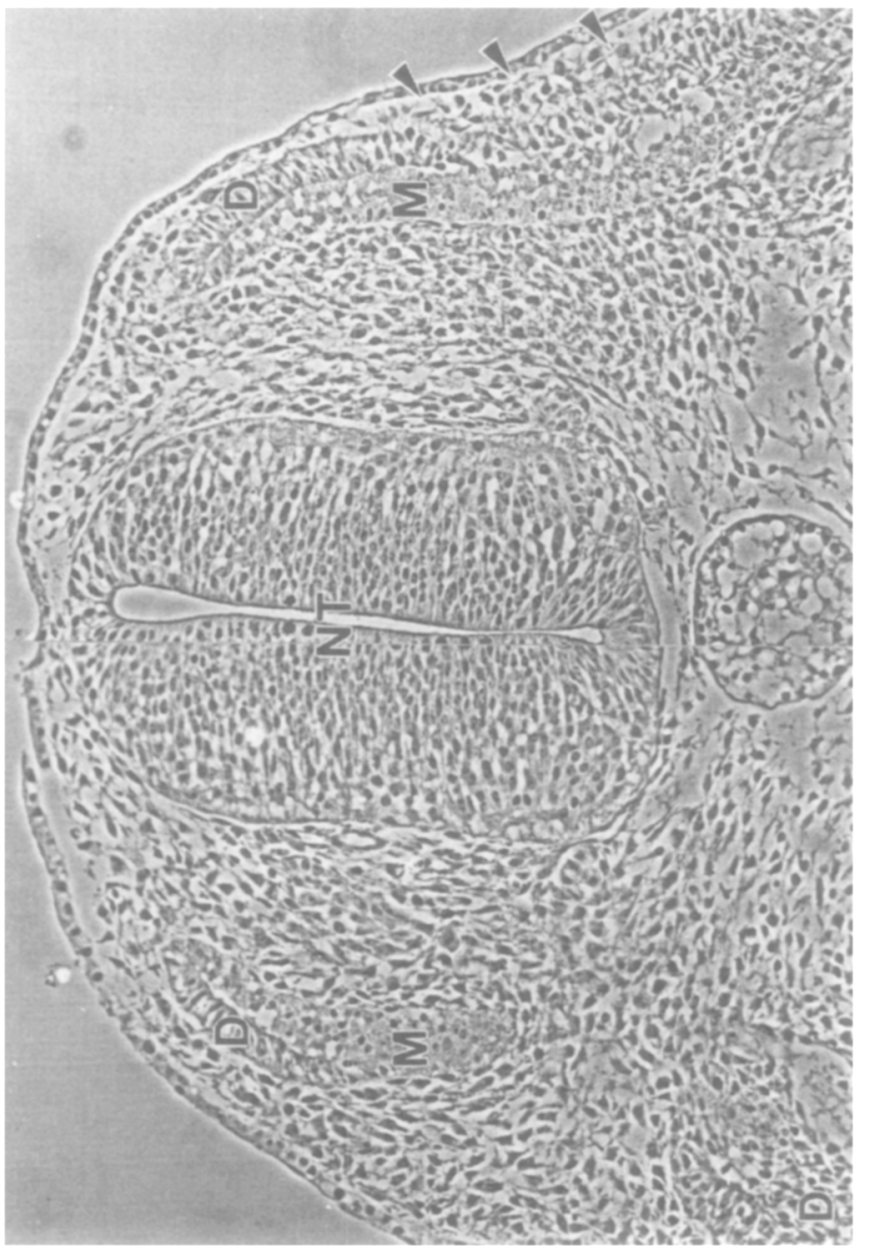


and the precocious migration of crest cells following partial dermamyotome deletions. Each of the four possibilities discussed below is consistent with the patterns of migration during normal and experimentally perturbed development; each makes predictions that are subject to test in future work.

First, the dermatome may produce, or cause the ectoderm to produce, some substance or substances that inhibit migration. When the dermatome is reduced in size by our operations, an inhibitory substance may be reduced below some threshold amount and allow crest cells to enter and traverse the path. The most obvious candidates for substances to render a path less permissive than an adjacent path are the molecular substrata on which crest cells migrate. For instance, chondroitin sulfate proteoglycans, which are found in the early dorsolateral path (Derby, 1978; Pintar, 1978; Lasky et al., 1991; Oakley and Tosney, 1991; Perris et al., 1991), are poor substrata for neural crest migration in culture (Erickson and Turley, 1983; Tucker and Erickson, 1984; Newgreen et al., 1986; Perris and Johansson, 1987) and in the embryo (Tucker, 1986). We predict that, if such substances inhibit early colonization of the path, they should be only transiently expressed in the dorsolateral path and should decline early following dermamyotome deletion.

Second, only the medial edge of the dermatome may normally prevent access to a path which is itself largely benign for advance. For instance, the medial dermatome may deposit relatively inhibitory substances locally and prevent crest cells from moving into the path. In most of our deletions the medial edge of the dermatome was partially absent and may have allowed crest cells to enter the path. Once in the path, the crest cells do rapidly colonize the more distal areas of the path and even migrate dorsal to remnants of the lateral dermatome. If only the medial dermatome prevents colonization of the early path, then deletion of medial dermatome alone should accelerate migration into the path.

Third, mesenchyme cells that spread into the space made by the deletion may be more permissive as a sub- stratum than the normal path. Certainly, during normal development, crest cells contact dermal mesenchyme cells in preference to dermatome and ectoderm. The expanded mesenchyme seen after deletions could derive from the adjacent sclerotome. However, if sclerotome cells had spread into the path we might have expected to see fewer crest cells in the posterior compartment since crest cells normally avoid posterior sclerotome, but we did not. The mesenchyme is likely to have come from the dermatome. Following dermamyotome deletions, dermis spreads widely from remnants of the epithelial dermatome and can even cross segmental boundaries (Tosney, 1987). Dermal mesenchyme is totally absent only in a central segment following complete deletion of at least three contiguous dermamyotomes (see Figs. 2A and 2B, in Tosney, 1987). Since dermamyotome deletions were not complete in the present study, much of the mesenchyme along the dorsolateral path could be dermal mesenchyme that spread from dermatome remnants into spaces made by the deletion. If such cells do provide a substratum that encourages earlier crest entry, then more complete dermamyotome deletions that fully prevent dermal mesenchyme from forming should prevent precocious entry of neural crest cells.

Fourth, dermal mesenchyme cells may provide a longdistance stimulant for neural crest advance. During normal development, dermis forms at the right time to attract crest cells: dermal cells first begin to disperse from the dermatome as or shortly before the first crest cells enter the dorsolateral path. Moreover, the dermis forms at the right place to provide a long-distance cue: dermal cells first disperse from the middle of the dermatome, at least $80 \mu \mathrm{m}$ from the point where crest cells enter the path. These cells are thus too distant to directly provide an essential substratum for crest cell advance. The dermal mesenchyme cells could provide a diffusible stimulant or could alter the extracellular matrix and render it more suitable for migration. The possibility that emerging dermis stimulates crest entry into the dorsolateral path is also consistent with migration patterns in operated embryos. Operations would not

FIG. 14. Matched fluorescent (A, B, C) and phase (D, E, F) micrographs show cross sections through the same stage 22 embryo that was mapped in Fig. 11. The dermatome was partially deleted from the left side, leaving the medial remnant of the dermatome (D) and some underlying myotome (M). The panoramic lower magnification views (A, D) show that HNK-1-reactive cells on the operated side are far advanced compared with their siblings on the normal side even though the medial tip of the dermatome still remains (arrows in A mark the distal extent of migration). Higher magnification shows in detail that there is a difference in the distribution of the mesenchyme in the dorsolateral pathway that correlates with the extent of neural crest cell migration. On the normal side mesenchyme cells (arrowheads in $D$, F) have dispersed from only the more lateral dermatome; they have not dispersed medially. On the operated side mesenchyme cells have spread into the region where the lateral dermamyotome has been excised and also occupy the region between the ectoderm and the distal tip of the remaining dermatome (arrowheads in E). The higher magnification also reveals that once crest cells are dispersed in mesenchyme, as they are in the medial segment of the dorsolateral path on the operated side (arrows in B), they infrequently contact the ectoderm or remaining dermatome (compare B and C). Scale bars $=100 \mu \mathrm{m}$. 

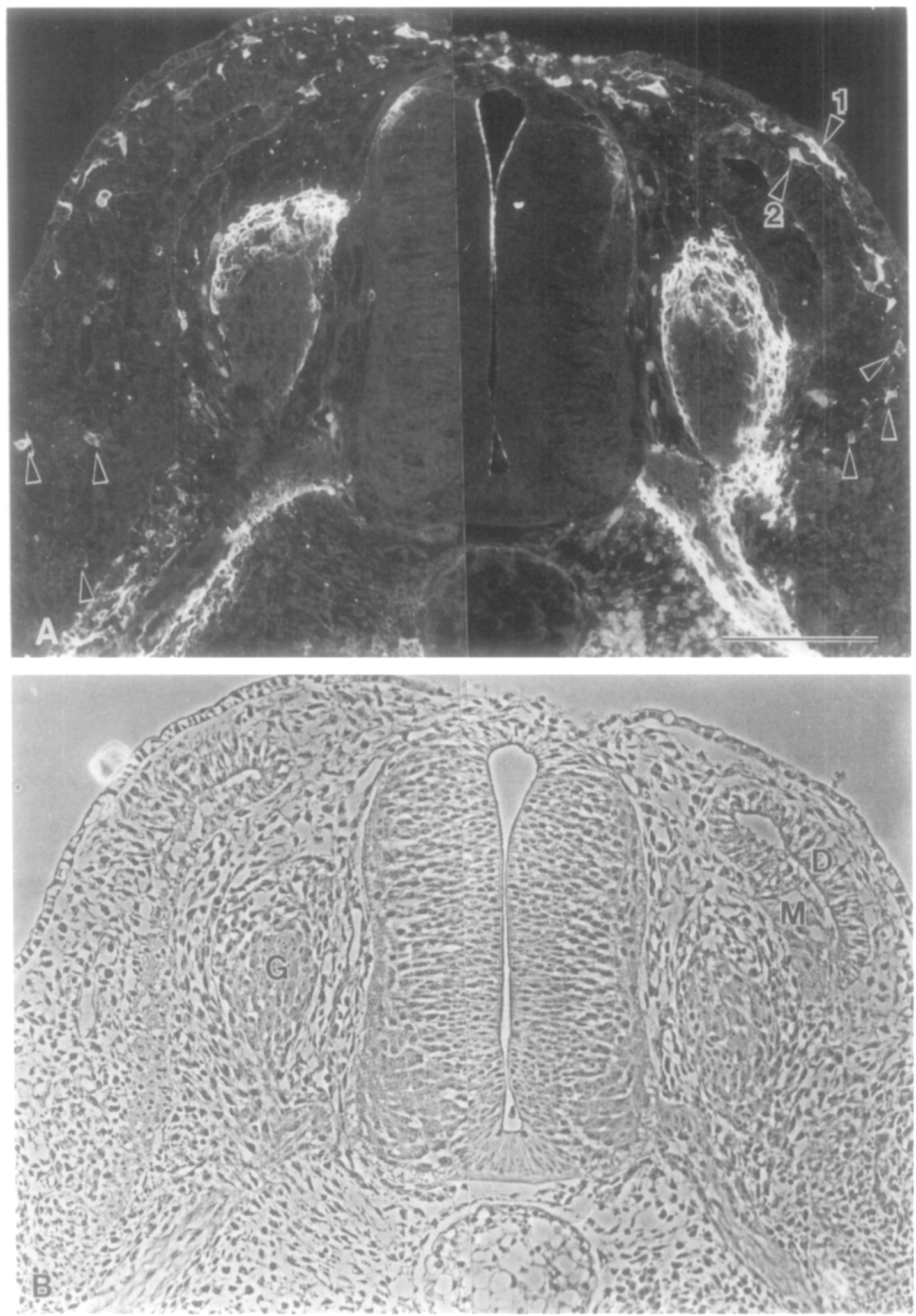

Fig. 15. Matching fluorescent (A) and phase (B) micrographs of a cross section through the stage 23.5 embryo that was mapped in Fig. 12 . The medial portion of the dermatome (D) and underlying myolome (M) remain on the operated (right) side. Abundant dermal mesenchyme has formed along the lateral portion of the dorsolateral path on the normal side. By this stage crest cells (arrowheads) on the normal side have caught up with the crest cells on the operated side and on both sides the most advanced cells are primarily dispersed within loose mesenchyme. Crest cells in the more medial portion of the path where few dermal mesenchyme cells have appeared contact both the ectoderm (arrowhead 1) and the dermatome (arrowhead 2). G, sensory ganglion. Seale bar $=100 \mu \mathrm{m}$. 
have eradicated such a cue because dermis from adjacent segments is likely to have invaded even those segments with extensive deletions.

The hypothesis that emerging dermis may supply an essential stimulation is consistent with the intriguing finding that the deletions only partially abolish the delay in crest entry. Dermamyotomes were deleted at stage 17 , shortly before crest cells begin to advance along the ventral path, but a precocious crest advance in to the dorsolateral path became obvious only at stage 20 , as dermatome begins to disperse. Crest cells between stages 18 and 20, before dermis has begun to form, still preferred ventral migration. If dermis provides an essential stimulatory cue, then crest cells should never enter the path after total eradication of dermis. Moreover, dermis should attract crest cells in suitable culture paradigms.

Several mechanisms may act in concert to control the crest cell invasion of the dorsolateral path. As in the guidance of axons (see Tosney and Oakley, 1990; Tosney, 1991), mechanisms that elicit an avoidance behavior and mechanisms that stimulate advance may both contribute to the patterns of neural crest cell dispersion. For instance, the deletion of the medial lip of the dermamyotome may remove a local inhibitory substance and give neural crest cells more direct access to a stimulatory cue from the emerging dermal mesenchyme. Regardless of the mechanism, our work clearly establishes that the dermatome is important to the selection of ventral versus dorsal paths and identifies predictions that can be tested to begin elucidating mechanisms.

We gratefully acknowledge the technical expertise of Susan Lester and Martha Spence. This research was supported by grants from the American Cancer Society (CD-60890 to C.A.E.) and NIH (NS-21308 to K.W.T.).

\section{REFERENCES}

Bronner-Fraser, M. (1986). Analysis of the early stages of trunk neural crest migration in avian embryos using monoclonal antibody HNK-1. Dev. Biol. 115, 11-55.

Cudennec, C. (1977). Reconnaissances cellulaires au cours du développement: Étude in vivo au moyen de chimeres interspécifiques chez l'embryon d'oiseau. Biol. Cellulaire 30, 41-48.

Derby, M. A. (1978). Analysis of glycosaminoglycans within the extracellular environments encountered by migrating neural crest cells. Dev. Biol. 66, 321-336.

Dorris, F. (1939). The production of pigment by chick neural crest in grafts to the 3 day limb bud. J. Exp. Zool. 80, 315-345.

Dushane, G. P. (1935). An experimental study of the origin of pigment cells in Amphibia. J. Exp. Zool. 72, 1-31.

Erickson, C. A. (1987). Behavior of neural crest cells on embryonic basal laminae. Dev. Biol. 120, 38-49.

Erickson, C. A., and Isseroff, R. R. (1989). Plasminogen activator activity is associated with neural crest cell motility in tissue culture. $J$. Exp. Zool. 251, 123-133.
Erickson, C. A., Loring, J. F', and Lester, S. M. (1989). Migratory pathways of HNK-1-immunoreactive neural crest cells in the rat embryo. Dev. Biol. 134, 112118.

Erickson, C. A., and Turley, E. A. (1983). Substrata formed by combinations of extracellular matrix components alter neural crest cell motility in vitro. J. Cell Sci. 61, 299-323.

Fairbairn, S., Gilbert, R., Ojakian, G., Schwimmer, R., and Quigley, J. P. (1985). The extracellular matrix of normal chick embryo fibroblasts: Its effects on transformed chick fibroblasts and its proteolytic degradation by the transformants. J. Cell Biol. 101, 1790-1798.

Fox, M. H. (1949). Analysis of some phases of melanoblast migration in the Barred Plymouth Rock embryos. Physiol. Zool. 12, 1-22.

Gehlsen, K. R., and Hendrix, M. J. C. (1987). Invasive characteristics of neural crest cells in vitro. Pigment Cell Res. 1, 16-21.

Gehlsen, K. R., Wagner, H. N., and Hendrix, M. J. C. (1984). Membrane invasion culture system (MICS). Med. Instrum. 18, 268-271.

Hamburger, V., and Hamilton, H. L. (1951). A series of normal stages in the development of the chick embryo. J. Morphol. 88, 49-92.

Hulley, P. A., Stander, C. S., and Kidson, S. H. (1991). Terminal migration and early differentiation of melanocytes in embryonic chick skin. Dev. Biol. 145, 182-194.

Lasky, C., Oakley, R. A., Dehnbostel, D., and Tosney, K. W. (1991). Experimental evidence that an inhibitory boundary delays neural crest migration. Soc. Neurosci. Abstr. 17, 761.

Le Dovarin, N. 1982. “The Neural Crest," pp. 259, Cambridge Univ. Press, Cambridge.

Löfberg, J., Ahlfors, K., and Fällström, C. (1980). Neural crest migration in relation to extracellular matrix organization in the embryonic axolotl trunk. Dev. Biol. 75, 148-167.

Loring, J. F., and Erickson, C. A. (1987). Neural crest cell migratory pathways in the trunk of the chick embryo. Dev. Biol. 121, 220-236.

Mackie, E. J., Tucker, R. P., Halfter, W., Chiquet-Ehrismann, R., and Epperlein, H. H. (1988). The distribution of tenascin coincides with pathways of neural crest cell migration. Development 102, 237-250.

Mayer, T. C. (1973). The migratory pathway of neural crest cells into the skin of mouse embryos. Dev. Biol. 34, 39-46.

Mayer, T. C., and Oddis, L. (1977). Pigment cell differentiation in embryonic mouse skin and isolated epidermis: An in vivo study. J. Exp. Zool. 202, 415-424.

Menoud, P. A., Debrot, S., and Schowing, J. (1989). Mouse neural crest cells secrete both urokinase-type and tissue-type plasminogen activators in vitro. Development 106, 685-690.

Newgreen, D. F. (1989). Physical influences on neural crest cell migration in avian embryos: Contact guidance and spatial restriction. Dev. Biol. 131, 136-148.

Newgreen, D. F., Scheel, M., and Kastner, V. (1986). Morphogenesis of sclerotome and neural crest in avian embryos: In vivo and in vitro studies on the role of notochordal extracellular material. Cell Tissue Res. 244, 299-313.

Oakley, R. A., and Tosney, K. W. (1991). Peanut agglutinin and chondroitin-6-sulfate are molecular markers for tissues that act as barriers to axon advance in the avian embryo. Dev. Biol. 147, 187206.

Perris, R., and Johansson, S. (1987). Amphibian neural crest cell migration on purified extracellular matrix components: A chondroitin sulfate proteoglycan inhibits locomotion on fibronectin substrates. J. Cell Biol. 105, 2511-2522.

Perris, K., Krotoski, D., Lallier, T., Domingo, C., Sorrell, J. M., and Bronner-Fraser, M. (1991). Spatial and temporal changes in the distribution of proteoglycans during avian neural crest development. Development 111, 583-599.

Pintar, J. E. (1978). Distribution and synthesis of glycosaminoglycans during quail neural erest morphogenesis. Dev. Biol. 67, 444-464. 
Quigley, J. P., Gold, L. I., Schwimmer, R., and Sullivan, L. M. (1987). Limited cleavage of cellular fibronectin by plasminogen activator purified from transformed cells. Proc. Natl. Acad. Sci. USA 84, 27762780.

Rawles, M. E. (1947). Origin of pigment cells from the neural crest in the mouse embryo. Physiol. Zool. 20, 248-266.

Rickmann, M., Fawcett, J. W., and Keynes, R. J. (1985). The migration of neural crest cells and the growth cones of motor axons through the rostral half of the chick somite. J. Embryol. Exp. Morphol. 90, 437-455.

Ris, H. (1941). An experimental study on the origin of melanophores in birds. Physiol. Zool. 14, 48-66.

Serbedzija, G. N., Bronner-Fraser, M., and Fraser, S. E. (1989). A vital dye analysis of the timing and pathways of neural crest cell migration. Development 106, 809-819.

Serbedzija, G. N., Fraser, S. E., and Bronner-Fraser, M. (1990). Pathways of trunk neural crest cell migration in the mouse embryo as revealed by vital dye labelling. Development 108, 605-612.

Teillet, M.-A. (1971), Recherches sur le mode de migration et la différenciation des mélanocytes cutanés chez l'embryon d'Oiseau: Étude expérimentale par la methode des greffes hétéro-spécifiques entre embryons de Caille et de Poulet. Ann. Embryol. Morphog. 4, 125-135.

Teillet, M.-A., Kalcheim, C., and Le Douarin, N. M. (1987). Formation of the dorsal root ganglia in the avian embryo: Segmental origin and migratory behavior of neural crest progenitor cells. Dev. Biol. $120,329-347$.

Tosney, K. W. (1978). The early migration of neural crest cells in the trunk region of the avian embryo: An electron microscopic study. Dev. Biol. 62, 317-333.

Tosney, K. W. (1987). Proximal tissues and patterned neurite outgrowth at the lumbosacral level of the chick embryo: Deletion of the dermamyotome. Dev. Biol. 122, 540-558.

Tosney, K. W. (1988). Somites and axon guidance. Scanning Microsc. 2, 427-442.

Tosney, K. W. (1991). Cells and cell-interactions that guide motor axons in the developing chick embryo. Bioessays 13, 17-23.
Tosney, K. W., and Oakley, R. A. (1990). The perinotochordal mesenchyme acts as a barrier to axon advance in the chick embryo: Implications for a general mechanism of axonal guidance. Exp. Neurol. 109, 75-89.

Tucker, R. P. (1986). The role of glycosaminoglycans in anuran pigment cell migration. J. Embryol. Exp. Morphol. 92, 145-164.

Tucker, R. P., and Erickson, C. A. (1984). Morphology and behavior of quail neural crest cells in artificial three-dimensional extracellular matrices. Dev. Biol. 104, 390-405.

Tucker, R. P., and Erickson, C. A. (1986). The control of pigment cell pattern formation in the California newt, Taricha torosa. J. Embryol. Exp. Morphol. 97, 141-168.

Valinsky, J. E., and Le Douarin, N. M. (1985). Production of plasminogen activator by migrating cephalic neural crest cells. EMBO J. 4, 1403-1406.

Vincent, M., Duband, J.-L., and Thiery, J.-P. (1983). A cell surface determinant expressed early on migrating neural crest cells. Dev. Brain Res. 9, 235-238.

Vincent, M., and Thiery, J.-P. (1984). A cell surface marker for neural crest and placodal cells: Further evolution in peripheral and central nervous system. Dev. Biol. 103, 468-481.

Watterson, R. L. (1942). The morphogenesis of down feathers with special reference to the developmental history of melanophores. Physiol. Zool. 15, 234-259.

Weiss, P., and Andres, G. (1952). Experiments on the fate of embryonic cells (chick) disseminated by the vascular route. J. Exp. Zool. $121,449-487$.

Weston, J. A. (1963). A radioautographic analysis of the migration and localization of trunk neural crest cells in the chick. Dev. Biol. 6, $279-310$.

Weston, J. A. (1970). The migration and differentiation of neural crest cells. Adv. Morphogen. 8, 41-114.

Weston, J. A., and Butler, S. L. (1966). Temporal factors affecting localization of neural crest cells in the chicken embryo. Dev. Biol. 14, 246-266.

Willier, B. H., and Rawles, M. E. (1940). The control of feather color pattern by melanophores grafted from one embryo to another of a different breed of fowl. Physiol. Zool. 13, 177-202. 